\title{
Optimizing the biomimetic synthesis of hydroxyapatite for the consolidation of bone using diammonium phosphate, simulated body fluid, and gelatin
}

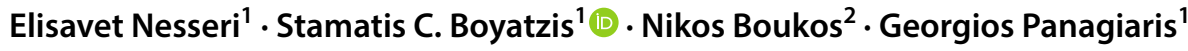

Received: 8 July 2020 / Accepted: 17 September 2020 / Published online: 26 October 2020

(c) Springer Nature Switzerland AG 2020

\begin{abstract}
Strategies involving the synthesis of hydroxyapatite (HAP) are significant in health and materials sciences, and lately, in heritage science. Conditions for the optimized heterogeneous formation of HAP for consolidating bone are investigated using a simple methodology with discs of calcium-containing starting materials and phosphate-containing reagent solutions; the results were evaluated against whole bone specimens. Diammonium phosphate (DAP) solutions with simulated body fluid (SBF) and gelatin as cofactors in all combinations were used in trials, while the products were characterized by microscopy, elemental microanalysis, X-Ray diffractometry, and Fourier transform infrared spectroscopy. The hypothesis that bone, SBF, and gelatin may biomimetically promote HAP formation was tested through a simple experimental design. The results showed that HAP is generally formed in mixtures with octacalcium phosphate (OCP), as well as calcium hydrogen phosphate dihydrate (brushite). The precipitation of carbonate HAP signals the formation of a biocompatible product in the cases where SBF and gelatin were employed as cofactors. Gelatin was found to further promote the product formation in most cases. It was shown that DAP, as well as its combination with gelatin, could predominantly form HAP in most trials, while OCP is co-crystallized in SBF-containing solutions.
\end{abstract}

Keywords Apatite $\cdot$ Bone $\cdot$ Consolidation $\cdot$ Biomimetic $\cdot$ Cultural heritage $\cdot$ Conservation

\begin{tabular}{|c|c|c|c|}
\hline \multicolumn{2}{|c|}{ Abbreviations } & SBF & Simulated Body Fluid \\
\hline ATR & Attenuated total reflection & $\mathrm{SI}$ & Supplementary Information \\
\hline DAP & Diammonium phosphate, $\left(\mathrm{NH}_{4}\right)_{2} \mathrm{HPO}_{4}$ & SEM & Scanning Electron Microscopy, \\
\hline DSP & Disodium phosphate, $\mathrm{Na}_{2} \mathrm{HPO}_{4}$ & XRD & X-ray diffractometry \\
\hline EDX & Energy Dispersive X-ray, & & \\
\hline HAP & Hydroxyapatite & & \\
\hline $\mathrm{C}-\mathrm{HAP}$ & Carbonate hydroxyapatite & 1 Ir & oduction \\
\hline $\mathrm{n}-\mathrm{HAP}$ & Nanocrystalline hydroxyapatite & & \\
\hline s-HAP & Stoichiometric hydroxyapatite & In th & tection of cultural heritage, methodologies have \\
\hline FTIR & Fourier transform infrared spectroscopy & bee & veloped employing chemical strategies for syn- \\
\hline IRSF & Infrared Splitting Factor & & $\mathrm{g}$ minerals such as organo-silicates, oxalates, and \\
\hline
\end{tabular}

Electronic supplementary material The online version of this article (https://doi.org/10.1007/s42452-020-03547-8) contains supplementary material, which is available to authorized users.

$\triangle$ Stamatis C. Boyatzis, sboyatzis@uniwa.gr; Elisavet Nesseri, elisavetnes@gmail.com; Nikos Boukos, n.boukos@inn.demokritos.gr; Georgios Panagiaris, gpanag@uniwa.gr|'Department of Conservation of Antiquities and Works of Art, University of West Attica, 12243 Egaleo, Greece. ${ }^{2}$ Institute of Nanoscience and Nanotechnology, National Center for Scientific Research "Demokritos", 15310 Aghia Paraskevi, Greece. 
Table 1 Calcium phosphates and selected properties ${ }^{\mathrm{a}}$

\begin{tabular}{|c|c|c|c|c|}
\hline Formula & Common names & $\mathrm{Ca} / \mathrm{P}$ & $\begin{array}{l}\text { Solubility } \\
\text { product } \\
\text { constant }\end{array}$ & Crystal structure \\
\hline \multicolumn{5}{|l|}{ Apatites } \\
\hline $\mathrm{Ca}_{10}\left(\mathrm{PO}_{4}\right)_{6}(\mathrm{OH})_{2}$ & Hydroxyapatite (HAP), stoichiometric & 1.67 & $\sim 1 \times 10^{-117}$ & Hexagonal/monoclinic \\
\hline $\mathrm{Ca}_{10}\left(\mathrm{PO}_{4}\right)_{6-y}\left(\mathrm{CO}_{3}\right)_{y}\left[\left(\mathrm{CO}_{3}\right)_{x+(1 / 2) y}(\mathrm{OH})_{2-2 x}\right]$ & $\begin{array}{l}\text { Carbonated Hydroxyapatite (HAP) (dahl- } \\
\text { ite) }\end{array}$ & Variable & $\sim 1 \times 10^{-103}$ & Pseudo-hexagonal/monoclinic \\
\hline $\mathrm{Ca}_{10-x}\left(\mathrm{PO}_{4}\right)_{6-x}\left(\mathrm{HPO}_{4}\right)_{x}(\mathrm{OH})_{2-x}$ & Hydroxy-apatite (HAP), nanocrystalline & Variable & $\sim 1 \times 10^{-116}$ & Pseudo-hexagonal/monoclinic \\
\hline $\mathrm{Ca}_{10}\left(\mathrm{PO}_{4}\right)_{6} \mathrm{~F}_{2}$ & Fluorapatite & 1.67 & $\sim 1 \times 10^{-119}$ & Hexagonal \\
\hline \multicolumn{5}{|l|}{ Other Phosphates } \\
\hline $\mathrm{CaHPO}_{4} \cdot 2 \mathrm{H}_{2} \mathrm{O}$ & $\begin{array}{l}\text { Dicalcium phosphate dihydrate (DCPD); } \\
\text { Brushite }\end{array}$ & 1.0 & $\mathrm{~K}_{\mathrm{sp}}=1 \times 10^{-7}$ & Monoclinic \\
\hline $\mathrm{Ca}_{8} \mathrm{H}_{2}\left(\mathrm{PO}_{4}\right)_{6} \cdot 5 \mathrm{H}_{2} \mathrm{O}$ & Octacalcium phosphate (OCP) & 1.33 & $\mathrm{~K}_{\mathrm{sp}}=1 \times 10^{-97}$ & Triclinic \\
\hline $\mathrm{Ca}_{3}\left(\mathrm{PO}_{4}\right)_{2}$ & Tricalcium phosphate (TCP) & 1.5 & $\mathrm{~K}_{\mathrm{sp}}=1 \times 10^{-26}$ & $\begin{array}{l}\text { a: amorphous } \\
\beta \text { : rhombohedral }\end{array}$ \\
\hline
\end{tabular}

${ }^{\text {a }}$ Data compiled from $[31,45,79-82]$

hydroxyapatite (HAP) for the consolidation of limestone and marble-containing objects in cultural heritage [1-6]; bone has been recently added to the list [7].

Bone is a composite material consisting of an organic fraction (mainly collagen and smaller amounts of non-collagenous proteins, lipids, and proteoglycans), an inorganic matrix (carbonate hydroxyapatite, or c-HAP), and water (structural, bound, free, and adsorbed) [8-11]. Structurally, it consists of small, elongated plate-like mineral crystals (up to $100 \mathrm{~nm}$ long, 2-4 $\mathrm{nm}$ thick) embedded in the protein matrix $[9,12,13]$.

Archaeological bone in its burial environment can seriously deteriorate through diagenesis, a complex process $[9,14-17]$ that leads to the damaging (a) of collagen by the action of micro-organisms and hydrolytic degradation and (b) of the inorganic matrix due to slow solubilization and recrystallization of minerals. The deterioration of any of the above two fractions exposes the other, thus affecting their profiles and crystallinity [9, 17-21]. Conventional approaches for bone consolidation involve the use of natural (wax, resins, gums) and synthetic materials (acrylic resins, polyvinyl acetals, and butyrals). These approaches, however, suffer from poor or uncontrolled penetration into the bone matrix, and therefore, offer temporary and sometimes problematic protection, potentially leading to severe damage due to yellowing, embrittlement, shrinkage, and delamination with time $[7,22]$.

The in situ formation of HAP on the surface of bone has been proposed as a biomimetic consolidation strategy [7, 23], using water-soluble diammonium phosphate (DAP) as a phosphate source on the one hand, and the bone surface as a calcium source and bio-scaffold simultaneously, on the other, for the synthesis and deposition of highly insoluble HAP. According to this strategy, in situ-formed HAP microcrystals can bridge ruptured or discontinued bone matrix phases, thus offering consolidation of the material.

A vital component of bone in vertebrates, hydroxyapatite, is one of the most common minerals in the living world $[9,24,25]$. Its synthetic formation has been widely exploited towards technological solutions in health and related materials sciences [26-30]. Stoichiometric HAP (s-HAP) can be formed according to the following reaction scheme, involving a calcium salt as a source of $\mathrm{Ca} 2+$ and hydrogen phosphate $\left(\mathrm{HPO}_{4}{ }^{2-}\right)$ :

$10 \mathrm{Ca}^{2+}+6 \mathrm{HPO}_{4}^{2-}+8 \mathrm{OH}^{-} \rightarrow \mathrm{Ca}_{10}(\mathrm{OH})_{2}\left(\mathrm{PO}_{4}\right)_{6} \downarrow+6 \mathrm{H}_{2} \mathrm{O}$

During the reaction, HAP, as the most thermodynamically stable form, precipitates according to a path that involves tricalcium phosphate $\left(\mathrm{Ca}_{3}\left(\mathrm{PO}_{4}\right)_{2}\right)$, brushite $\left(\mathrm{CaHPO}_{4} \cdot 2 \mathrm{H}_{2} \mathrm{O}\right)$ and octacalcium phosphate $\left(\mathrm{Ca}_{8} \mathrm{H}_{2}\left(\mathrm{PO}_{4}\right)_{6}\right.$ - $5 \mathrm{H}_{2} \mathrm{O}$ ) as precursor phases $[6,31-33$ ] (see Table 1). During HAP synthesis, the characterization of the actual phosphate product depending on the conditions (the type of ionic solution, $\mathrm{pH}$, time of application), in combination with a conclusive analytical investigation, is crucial.

For evaluating the successful formation of stoichiometric HAP, Scanning Electron Microscopy with Energy Dispersive X-Ray Analysis (SEM-EDX), X-ray diffractometry (XRD), and Fourier Transform Infrared Spectroscopy (FTIR) is typically employed. A first criterion is the $\mathrm{Ca} / \mathrm{P}$ ratio, which is typically estimated through microelemental elemental analysis (SEM-EDX), which, for s-HAP, is 1.67. Deviation from this value may suggest that other phosphate phases are also produced, such as nanocrystalline and carbonate hydroxyapatite (n-HAP and c-HAP, respectively) as well as octacalcium phosphate (OCP). 


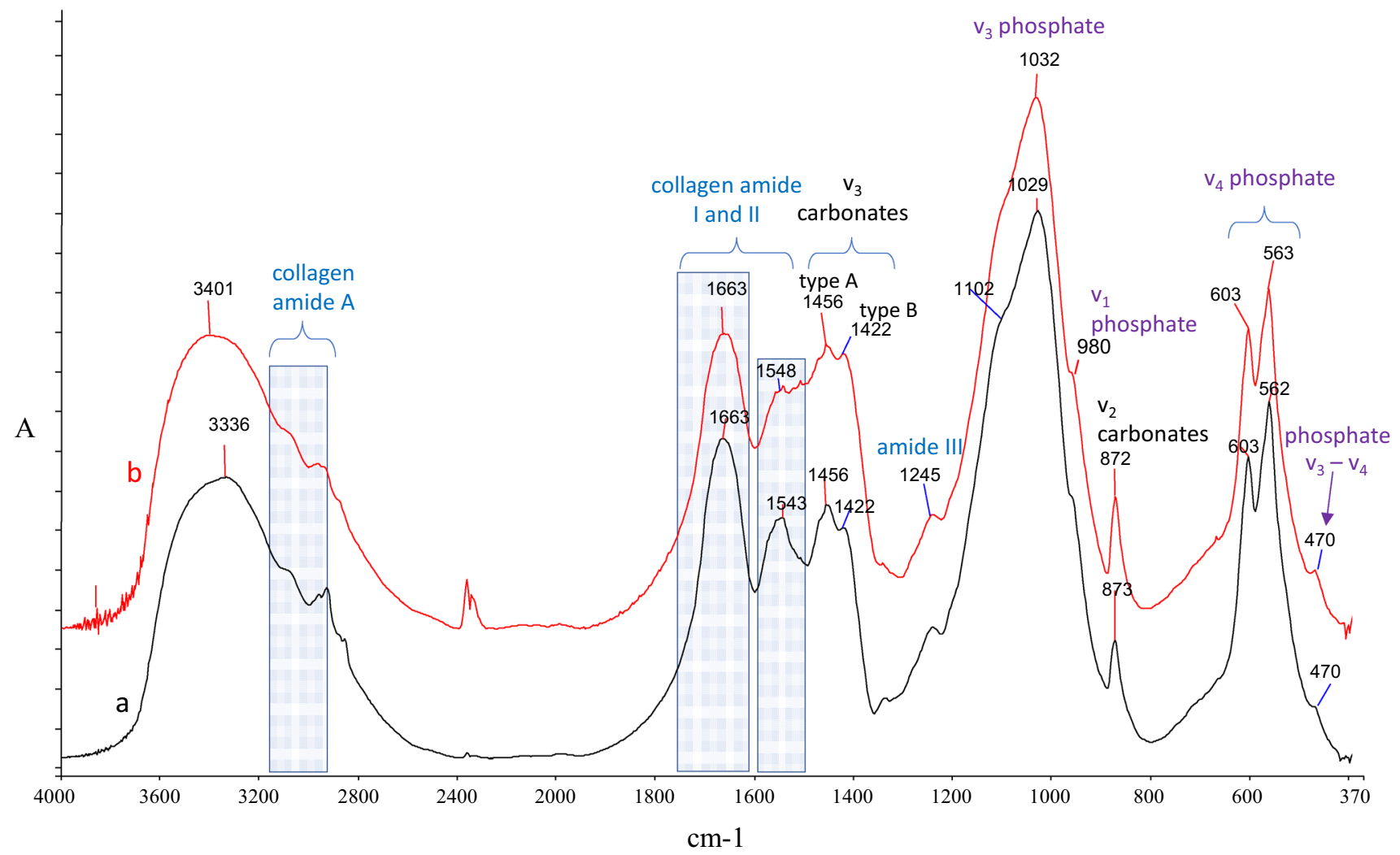

Fig. $1 \mathrm{KBr}-\mathrm{FTIR}$ spectra of a modern deer cortical bone; $\mathbf{b}$ archaeological human cortical bone of proto-Byzantine period, burial site around Kozani, North-Eastern Greece

X-ray diffractometry (XRD) and Fourier Transform Infrared Spectroscopy (FTIR) are the main techniques for characterizing the condition of archaeological bone in the burial environment [34-39], as well as HAP, in particular $[13,30]$. In s-HAP, peaks are well-resolved, while in n-HAP and c-HAP, imperfections in the crystal lattice are reflected in broader envelopes [31, 40]. In XRD spectra, the more prominent peaks of (211), (112), (300) and (202) crystalline planes with d-spacings at 3.32, 2.93, 2.79 and $2.72 \AA$, respectively, are broadened and sometimes overlapping [31] (see, for example, spectra recorded through the trials of this work in Fig. $2 c-d$ ). Additionally, line shape analysis of XRD peaks provides information on crystallinity; a widely accepted methodology involves the correlation of the Full-Width Half Maximum (FWHM) of spectra with crystal size [41-43].

Similarly, in FTIR spectra, the two components of the $v_{3}$ phosphate vibrational mode are mutually overlapping, allowing a maximum at $\sim 1020 \mathrm{~cm}^{-1}$ and a shoulder at $1100 \mathrm{~cm}^{-1}$ (see spectra ii and v in Fig. 2a) [44, 45]. On the other hand, the $v_{4}$ vibrational mode is typically observed as a resolved doublet, in which, the 'valley' between the doublet components $\left(604\right.$ and $563 \mathrm{~cm}^{-1}$, as seen in the same spectra), typically expressed as the infrared splitting factor (IRSF), is often used to assess the crystallinity of $\operatorname{HAP}[1,13,25,34,46-49]$. In bone c-HAP, carbonates occur in two distinct types: type A for those replacing hydroxide ions of the stoichiometric HAP structure (with a maximum of their $v_{3}$ vibration at $\sim 1456 \mathrm{~cm}^{-1}$ ), and type $B$ for those replacing phosphates (at $\sim 1415 \mathrm{~cm}^{-1}$ ) [31, 40, 50-53] as seen in Fig. 1. Values and assignments are listed in Table 2. Semi-quantification of carbonate in c-HAP can be achieved by calculating the carbonate index, i.e. the ratio of the type $B$ carbonate absorption height over that of phosphate $v_{3}[49,54,55]$. Also, an estimate of the type $A /$ type $B$ ratio can be obtained by comparing the areas under the deconvoluted components of the $\mathrm{v}_{2}$ carbonate vibration at $880 \mathrm{~cm}^{-1}$ (type A) and 873 (type B) $[21,56]$.

Laboratory synthesis of HAP has been achieved following various methods such as wet chemical precipitation from calcium hydroxide and phosphoric acid as well as multiphase systems in hydrothermal and sol-gel synthesis methods [1, 43, 57-61]. Additionally, biomimetic approaches have been developed, aiming at forming various apatites, mainly for health applications, such as bone regeneration $[27,62,63]$ and bio-compatible coatings 
Table 2 Infrared peaks mentioned in text with their assignments

\begin{tabular}{|c|c|c|}
\hline Infrared peak $\left(\mathrm{cm}^{-1}\right)^{b}$ & Peak assignment ${ }^{a}$ & Notes \\
\hline \multicolumn{3}{|l|}{ Bone material } \\
\hline \multicolumn{3}{|l|}{ Organic fraction } \\
\hline 3082,2968 & $v \mathrm{NH}, v \mathrm{NH}_{2}$ & Collagen \\
\hline 2929,2878 & $v(\mathrm{C}-\mathrm{H})$ & In alkyl chains of fatty components in bone \\
\hline 1664 & $\begin{array}{l}v \mathrm{C}=\mathrm{O} \text { with contributions from } v \mathrm{C}-\mathrm{N} \text { and } \delta \mathrm{N}-\mathrm{H} \text {; } \\
\text { Amide I }\end{array}$ & Collagen \\
\hline 1542 & $v C-\mathrm{N}$ with contributions from $\delta_{i p} \mathrm{~N}-\mathrm{H}$ : Amide II & Collagen \\
\hline 1243 & $\begin{array}{l}\mathrm{vC}-\mathrm{N}+\delta \mathrm{N}-\mathrm{H} \text { with contributions from } \mathrm{vC}-\mathrm{C} \\
\text { and } \delta_{\mathrm{ip}} \mathrm{C}=\mathrm{O} \text { : Amide III }\end{array}$ & Collagen \\
\hline \multicolumn{3}{|l|}{ Inorganic fraction } \\
\hline$\sim 3200$ (br) & $\mathrm{vOH}$ & Apatitic hydroxide \\
\hline (1546), 1458 & $v_{3} \mathrm{CO}_{3}{ }^{2-}$ & $\begin{array}{l}\text { Carbonate, type } A \text { (hydroxide substitution) in } \\
\text { C-HAP, doubly degenerate }\end{array}$ \\
\hline (1465), 1415 & $v_{3} \mathrm{CO}_{3}{ }^{2-}$ & $\begin{array}{l}\text { Carbonate, type } B \text { (phosphate substitution) in } \\
\text { C-HAP, doubly degenerate }\end{array}$ \\
\hline 1111(sh), (1070), 1031 & $v_{3} \mathrm{PO}_{4}^{3-}$ & $\begin{array}{l}\text { HAP, triply degenerate. Resolution related to } \\
\text { crystallinity }\end{array}$ \\
\hline 980 & $v_{1} \mathrm{PO}_{4}^{3-}$ & Hydroxyapatite \\
\hline 880 & $\mathrm{v}_{2} \mathrm{CO}_{3}{ }^{2-}$ & Carbonate, type A in c-HAP \\
\hline 872 & $\mathrm{v}_{2} \mathrm{CO}_{3}{ }^{2-}$ & Carbonate, type B in c-HAP \\
\hline 604,562 & $v_{4} \mathrm{PO}_{4}^{3-}$ & HAP \\
\hline \multicolumn{3}{|l|}{ Octacalcium phosphate } \\
\hline 3400 & $\mathrm{vOH}$ & Hydroxide \\
\hline $1161,1105,1055,1032,1000$ & $v_{3} \mathrm{PO}_{4}^{3-}$ & \\
\hline 900 & $\mathrm{v}_{1} \mathrm{PO}_{4}^{3-}$ & \\
\hline 586,546 & $v_{4} \mathrm{PO}_{4}^{3-}$ & \\
\hline \multicolumn{3}{|c|}{ Dicalcium phosphate dihydrate (brushite) } \\
\hline $3544,3499,3291,3165$ & $\mathrm{vOH}$ & Crystalline $\mathrm{H} 2 \mathrm{O}$ \\
\hline 1651 & $\delta \mathrm{H}-\mathrm{O}-\mathrm{H}$ & Crystalline $\mathrm{H} 2 \mathrm{O}$ \\
\hline $1218,1138,1062,988$ & $\mathrm{v}_{3} \mathrm{PO} 4$ & \\
\hline 875,792 & $\mathrm{v}_{1} \mathrm{PO} 4$ & \\
\hline 590,528 & $\mathrm{v}_{4} \mathrm{PO} 4$ & \\
\hline
\end{tabular}

${ }^{a}$ Data compiled from $[9,31,45,64,83]$ and this work

${ }^{b}$ Values in parentheses denote overlapped peaks

for bone and dental implants [64-66]. In this aspect, wet chemical routes based on Simulated body fluid (SBF), a supersaturated cocktail that resembles the ionic content of blood serum, has been proposed [57, 59, 62, 67]. The SBF approach is adopted as an ionic environment that promotes the synthesis of $\operatorname{HAP}[58,59,62,67,68]$, while protocols for its preparation are generally under scrutiny and being constantly revised [27, 31, 62, 69-71].

Alternatively, strategies involving molecular scaffolds that facilitate the right ionic profile towards HAP, thus producing HAPs structurally and morphologically similar to those in bone, have also been proposed $[2,7,64]$.

This work aims at investigating the working conditions for efficient in situ precipitation of hydroxyapatite on the surface of bone aiming at its consolidation. A simple experimental methodology is applied, employing the biomimetic scaffold offered by bone, in combination with cofactors such as SBF and gelatin. The compatibility concept is also questioned as to whether nanocrystalline carbonate hydroxyapatite, similar to the one existing in bone, can be formed.

\section{Materials and techniques}

\subsection{Materials}

Water, $\mathrm{HPLC}$ grade, was purchased from Honeywell. $\mathrm{CaCO}_{3}$, $\mathrm{CaCl}_{2}$, and $\mathrm{NaCl}$ were purchased from Merck. Diammonium phosphate (DAP) Disodium phosphate $\left(\mathrm{Na}_{2} \mathrm{HPO}_{4}\right)$ was 


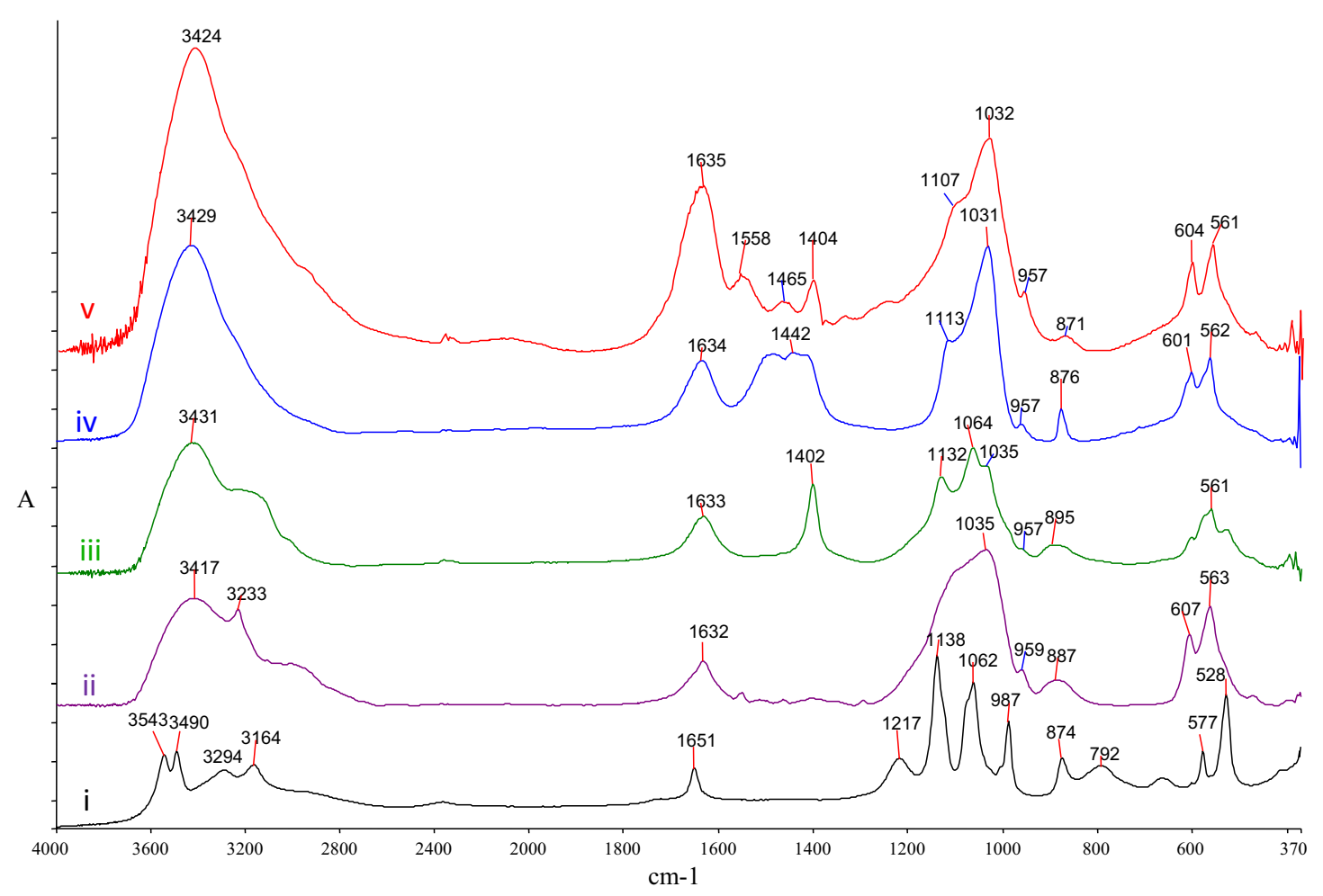

(a)

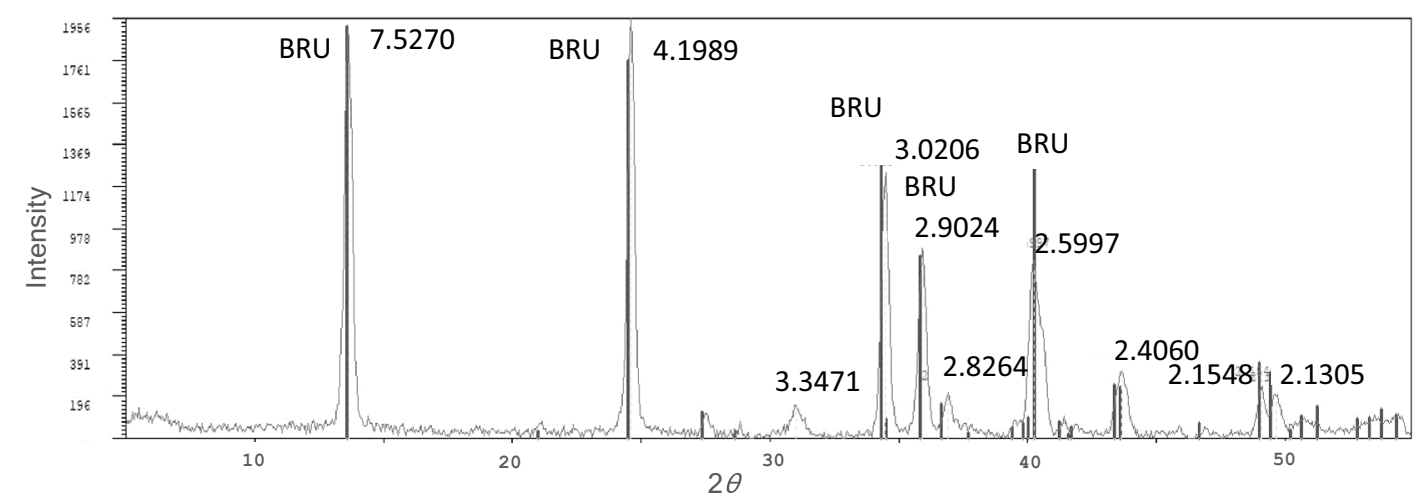

(b)

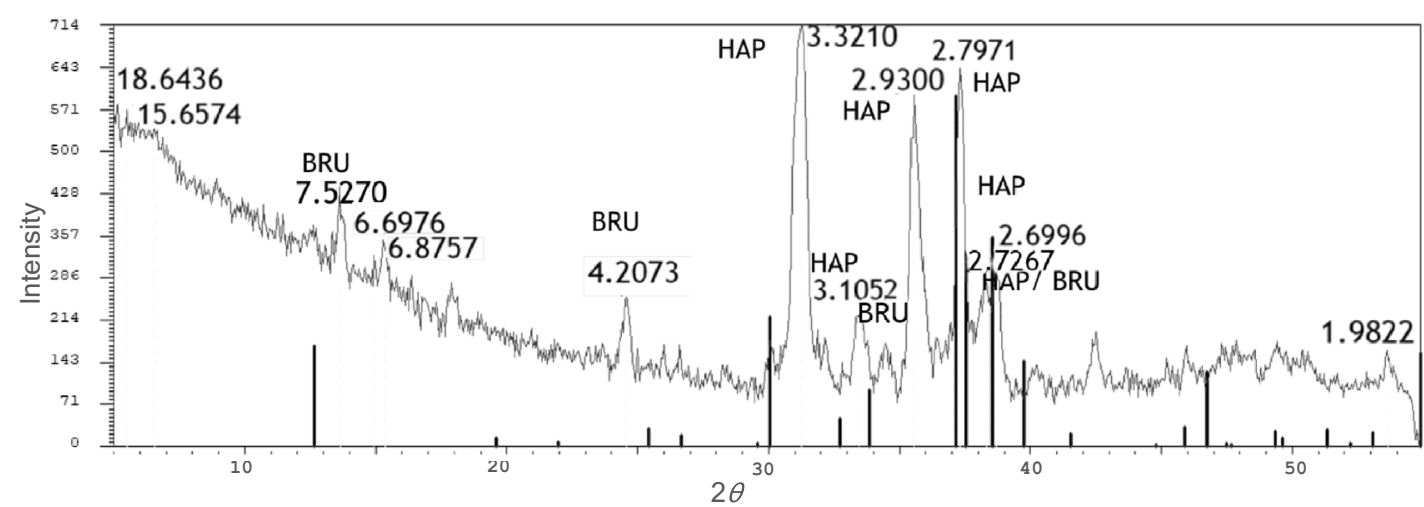

(c)

Fig. 2 a KBr-FTIR spectra of products after SBF-based synthesis in solution; (i) trial SBF-1; (ii) SBF-2; (iii) SBF-3, (iv) SBF-4 and (v) SBF5. $\mathbf{b}$ XRD spectrum of products after trial SBF-1; $\mathbf{c}$ XRD spectrum of products after trial SBF-2; $\mathbf{d}$ XRD spectrum of products after trial SBF-5. In all XRD spectra, $2 \theta$ angles are relative to CoKa ${ }_{1}$ wavelength 


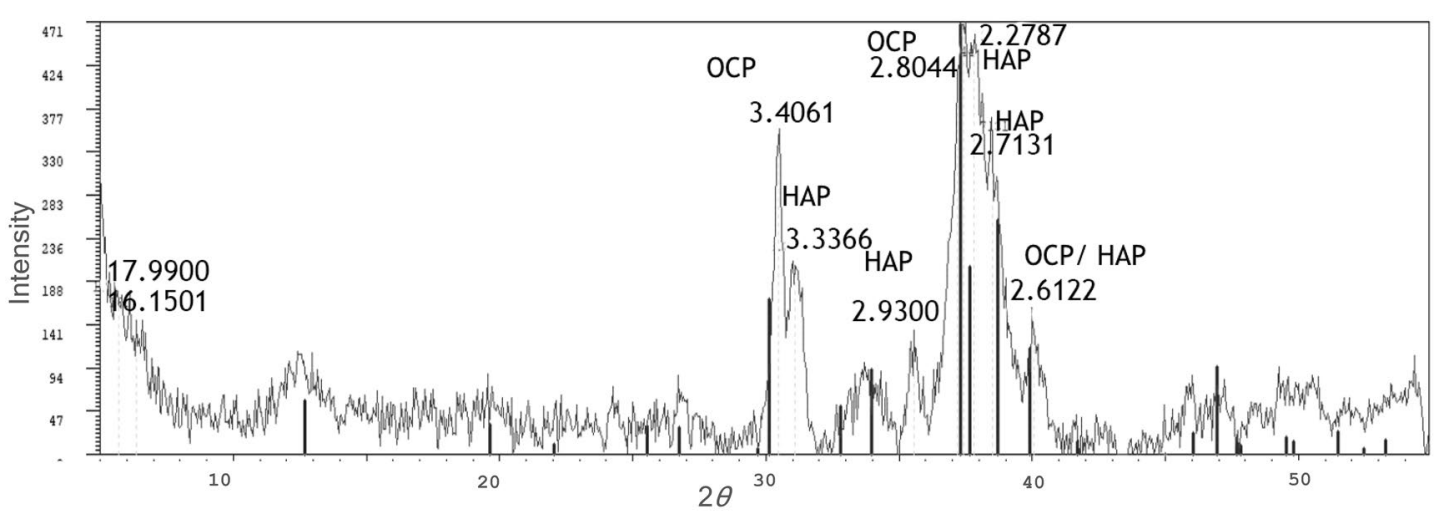

(d)

Fig. 2 (continued)

purchased from Sigma-Aldrich. $\mathrm{HCl}(36 \% \mathrm{w} / \mathrm{v})$ was purchased from Fluka.

\subsection{Trials for the formation of hydroxyapatite}

\subsubsection{Preparation of specimens}

Hydraulic press For the preparation of discs, a standard $13 \mathrm{~mm}$ evacuable pellet die and disc holder with rectangular mount, and a 15 ton (max) manual hydraulic press, all provided by Specac (Orpington, Kent, UK) were used.

13- $\mathrm{mm}$ diameter disc specimens: (a) Calcium carbonate(calcite, Merck) powder was manually finely ground with a pestle and mortar and (b) bone powder was prepared by gently grinding young Roe deer bone (kindly offered by DRAFA, Denmark) with a motorized grinder using the lowest speed available to avoid the release of excessive heat.

These were accordingly pressed and formed to $13-\mathrm{mm}$ discs using a standard FTIR-disc mold and after hydraulic pressing at 10 and $3 \mathrm{tn}$, respectively.

Whole bone specimens: a seagull leg bone (found in presumably naturally aged condition in the open air, in which had remained for an unspecified period) was cut in approximately $15 \mathrm{~mm}$-long pieces of variable thickness and were consequently used without further workup.

\subsubsection{SBF-based HAP synthesis}

2.2.2.1 Preparation of simulated body fluid (SBF) SBF was prepared in HPLC-grade water by sequentially mixing $\mathrm{NaCl}(0.3319 \mathrm{~g}), \mathrm{Na}_{2} \mathrm{HPO}_{4}(0.0071 \mathrm{~g}), \mathrm{NaHCO}_{3}(0.1134 \mathrm{~g})$, $\mathrm{Na}_{2} \mathrm{SO}_{4}(0.0035 \mathrm{~g}), \mathrm{KCl}(0.1862 \mathrm{~g}), \mathrm{CaCl}_{2}(0.0138 \mathrm{~g})$ and $\mathrm{MgCl}_{2} \cdot 6 \mathrm{H}_{2} \mathrm{O}(0.0152 \mathrm{~g})$, with until $50 \mathrm{ml}$ final volume with no further stirring. The $\mathrm{pH}$ was regulated at 7.3-7.5 by adding hydrochloric acid (1 $\mathrm{M}$, dropwise until $\mathrm{pH} 7.3-7.5$ ).
The above route was based on previous work [31, 58, 59, 69]. This way, a solution containing ions in the required concentrations was prepared and used as required (see Sect. 3.1).

2.2.2.2 Synthesis of HAP using SBF The precipitation of HAP was generally achieved by adding a calcium salt $\left(\mathrm{CaCl}_{2}\right)$ and a phosphate source in the form of watersoluble salt: $\mathrm{Na}_{2} \mathrm{HPO}_{4}$ (disodium phosphate or DSP and $\left(\mathrm{NH}_{4}\right)_{2} \mathrm{HPO}_{4}$ (diammonium phosphate or DAP) to previously prepared SBF solutions; the reaction proceeds according to Eq. 1.

Several variations were considered and attempted, from which, selected trials are herewith presented:

2.2.2.3 DSP as a phosphate source Stock solutions of $\mathrm{CaCl}_{2}$ ( $0.5 \mathrm{M}$, by adding $1.3875 \mathrm{~g}$ of solid $\mathrm{CaCl}_{2}$ in $10 \mathrm{ml}$ of $\mathrm{H} 2 \mathrm{O}$ ) and DSP $\left(0.3 \mathrm{M}\right.$, by adding $1.3349 \mathrm{~g}$ of solid $\mathrm{Na}_{2} \mathrm{HPO}_{4}$ in $10 \mathrm{ml} \mathrm{H} 2 \mathrm{O}$ ) were prepared.

Trial SBF-1: To $25 \mathrm{ml}$ of SBF solution (see above), $5 \mathrm{ml}$ of the $0.5 \mathrm{M} \mathrm{CaCl}_{2}$ solution was added, followed by dropwise addition (1 drop/10 s, approx.) of the $0.3 \mathrm{M} \mathrm{DSP}$ solution at $36.5^{\circ} \mathrm{C}$ with no stirring, until a cloudy suspension is formed.

Trial SBF-2: To $25 \mathrm{ml}$ of SBF solution, $10 \mathrm{ml}$ of the $0.5 \mathrm{M}$ $\mathrm{CaCl}_{2}$ solution was added, followed by dropwise addition (1 drop/10 s, approx.) of the $0.3 \mathrm{M} \mathrm{DSP}$ solution at $36.5^{\circ}$ $\mathrm{C}$ under continuous stirring until $10 \mathrm{ml}$ of the phosphate was consumed.

2.2.2.4 DAP as a phosphate source Stock solutions of $\mathrm{CaCl}_{2}\left(1.25 \mathrm{M}\right.$, by adding $1.3875 \mathrm{~g}$ of solid $\mathrm{CaCl}_{2}$ in $10 \mathrm{ml}$ of $\mathrm{H} 2 \mathrm{O})$ and $\left(\mathrm{NH}_{4}\right)_{2} \mathrm{HPO}_{4}$ or diammonium phosphate, DAP $\left(0.75 \mathrm{M}\right.$ by adding $0.99 \mathrm{~g}$ of solid $\left(\mathrm{NH}_{4}\right)_{2} \mathrm{HPO}_{4}$ in $10 \mathrm{ml}$ of $\mathrm{H} 2 \mathrm{O}$ ) were prepared.

Trial SBF-3: To $25 \mathrm{ml}$ of SBF solution, $10 \mathrm{ml}$ of the $1.25 \mathrm{M}$ $\mathrm{CaCl}_{2}$ solution was added followed by dropwise addition 
(1 drop/5 s, approx.) of the $0.75 \mathrm{M} \mathrm{DAP}$ solution at $36.5^{\circ} \mathrm{C}$ under continuous stirring until $10 \mathrm{ml}$ of the phosphate was consumed (attempt No8).

Trial SBF-3: To $25 \mathrm{ml}$ of SBF solution, $10 \mathrm{ml}$ of the $1.25 \mathrm{M}$ $\mathrm{CaCl}_{2}$ solution was added followed by dropwise addition (1 drop/5 s, approx.) of the $0.75 \mathrm{M} \mathrm{DAP}$ solution at $36.5^{\circ} \mathrm{C}$ under continuous stirring until $10 \mathrm{ml}$ of the phosphate was consumed (attempt No8).

SBF-5: To $25 \mathrm{ml}$ of SBF solution, $0.1 \mathrm{~g}$ of gelatin was added. Then, $5 \mathrm{ml}$ of the $1.25 \mathrm{M} \mathrm{CaCl}_{2}$ solution was added, followed by dropwise addition ( 1 drop $/ 5 \mathrm{~s}$, approx.) of the $0.75 \mathrm{M}$ DAP solution at $36.5^{\circ} \mathrm{C}$ with no stirring, until a cloudy suspension is formed, and $10 \mathrm{ml}$ of the phosphate was consumed.

Products were characterized by SEM-EDX, XRD, and $\mathrm{KBr}$-FTIR.

\subsection{In situ synthesis of hydroxyapatite (HAP) on calcite and bone powder discs}

In all trials for in situ deposition of HAP, the following reagent solutions were made: (a) diammonium phosphate (DAP), $0.5 \mathrm{M}$, solution (prepared by adding $0.33 \mathrm{~g}$ of solid $\left(\mathrm{NH}_{4}\right)_{2} \mathrm{HPO}_{4}$ to $5 \mathrm{ml}$ of $\mathrm{H} 2 \mathrm{O}$ ); (b) DAP/SBF: to $5 \mathrm{ml}$ of the DAP solution, $5 \mathrm{ml}$ of previously prepared SBF solution (see above) was added; (c) DAP/gelatin: to $5 \mathrm{ml}$ of the DAP solution, $5 \mathrm{ml}$ of $0.1 \% \mathrm{w} / \mathrm{v}$ aqueous gelatin solution was added; (d) DAP/SBF/gelatin: to $5 \mathrm{ml}$ of the DAP solution, $5 \mathrm{ml}$ of previously prepared SBF solution (see above) and $5 \mathrm{ml}$ of $0.1 \% \mathrm{w} / \mathrm{v}$ aqueous gelatin solution was added, $5 \mathrm{ml}$ of $0.1 \% \mathrm{w} / \mathrm{v}$ aqueous gelatin solution was added.

In all cases, $12 \mathrm{~mm}$ discs were prepared according to the standard procedure with the use of a dedicated disc mold and a SpecAc (Orpington, Kent, UK) manual hydraulic press.

\section{a. Control trials on calcite discs}

In the control experiments, four pressed $\mathrm{CaCO}_{3}$ (calcite) powder discs were prepared (see above). The disc was divided into four approximately equal pieces.

Trials $\mathrm{Ca}-1$ to 4: each of the above-described discs were immersed in a $10 \mathrm{~mL}$ DAP (trial Ca-1), a $10 \mathrm{~mL}$ DAP/SBF solution (trial Ca-2), a $10 \mathrm{~mL} \mathrm{DAP/gelatin} \mathrm{solution} \mathrm{(trial}$ Ca-3), and finally, a $10 \mathrm{~mL} \mathrm{DAP/SBF/gelatin} \mathrm{solution} \mathrm{(trial}$ Ca-4). After 5 min immersion time, the discs were removed and accordingly examined with optical microscopy, and characterized with SEM-EDX, ATR-FTIR, and XRD.

Later, additional quantities of the DAP, DAP/SBF, DAP/ gelatin, and $\mathrm{DAP} / \mathrm{SBF} /$ gelatin solutions were respectively added dropwise ( 3 drops ( $0.05 \mathrm{ml}$ each) maximum) and the discs were similarly examined and characterized (trials Ca-5, 67 and 8, respectively).

\section{b. Trials on bone powder discs}

Four pressed $13 \mathrm{~mm}$ bone powder discs were prepared (see above) (trials BP-1 to 4).

Trials BP-1 to 4: the previously described discs were treated and accordingly examined and analyzed similarly to the Ca-1 to 4 trials. Products were characterized by SEM-EDX and ATR-FTIR.

c. Trials on $\mathrm{Ca}^{2+}$-enriched pressed bone powder disks

Trials $B P C a-1$ to 4: Four pressed $13 \mathrm{~mm}$ bone powder discs were prepared similarly to those in trials BP- 1 to 4 and were calcium-enriched by adding three drops of a $6.5 \% \mathrm{v} / \mathrm{w} \mathrm{CaCl}_{2} / \mathrm{H}_{2} \mathrm{O}$ solution to each; the calcium salt solution is estimated to be in excess with respect to the dripped DAP quantity. Products were characterized by SEM-EDX, XRD, and ATR-FTIR.

\subsection{In situ synthesis of hydroxyapatite on calcium-enriched bone specimens}

Trials $B-1$ to 4 : four seagull bone specimens were cut from the same part of the bird's leg bone in approx. $3.0-4.0 \mathrm{~mm}$ length and $0.5-1.0 \mathrm{~mm}$ diameter; each of these was immersed in DAP, DAP/SBF, DAP/gelatin, and DAP/SBF/ gelatin solutions (concentrations the same as above) and left with no stirring for $24 \mathrm{~h}$. Products were characterized by SEM-EDX and KBr-FTIR.

\section{5 analysis techniques}

\subsubsection{Scanning electron microscopy-Energy-dispersive $\mathrm{x}$-ray analysis (SEM-EDX)}

In all cases, a JEOL JSM-6510LV Scanning Electron Microscope equipped with an Oxford X-act XEDSM energy dispersive X-Ray analyzer applied vacuum: $40 \mathrm{~Pa}$. Specimens were inserted in the system's sample chamber without further workup.

\subsubsection{Transmission electron microscopy (TEM)}

A Thermo-Fisher Scientific Talos F200i Transmission Electron Microscope operating at $200 \mathrm{kV}$ accelerating voltage. and equipped with a window-less Bruker 6 T|100 energy dispersive X-ray micro analyzer was used. The TEM specimens were prepared by scraping off the material to be examined, subsequent grinding by mortar and pestle in ethanol and drop casting $1 \mu$ l on copper TEM grids coated with a thin carbon film. 


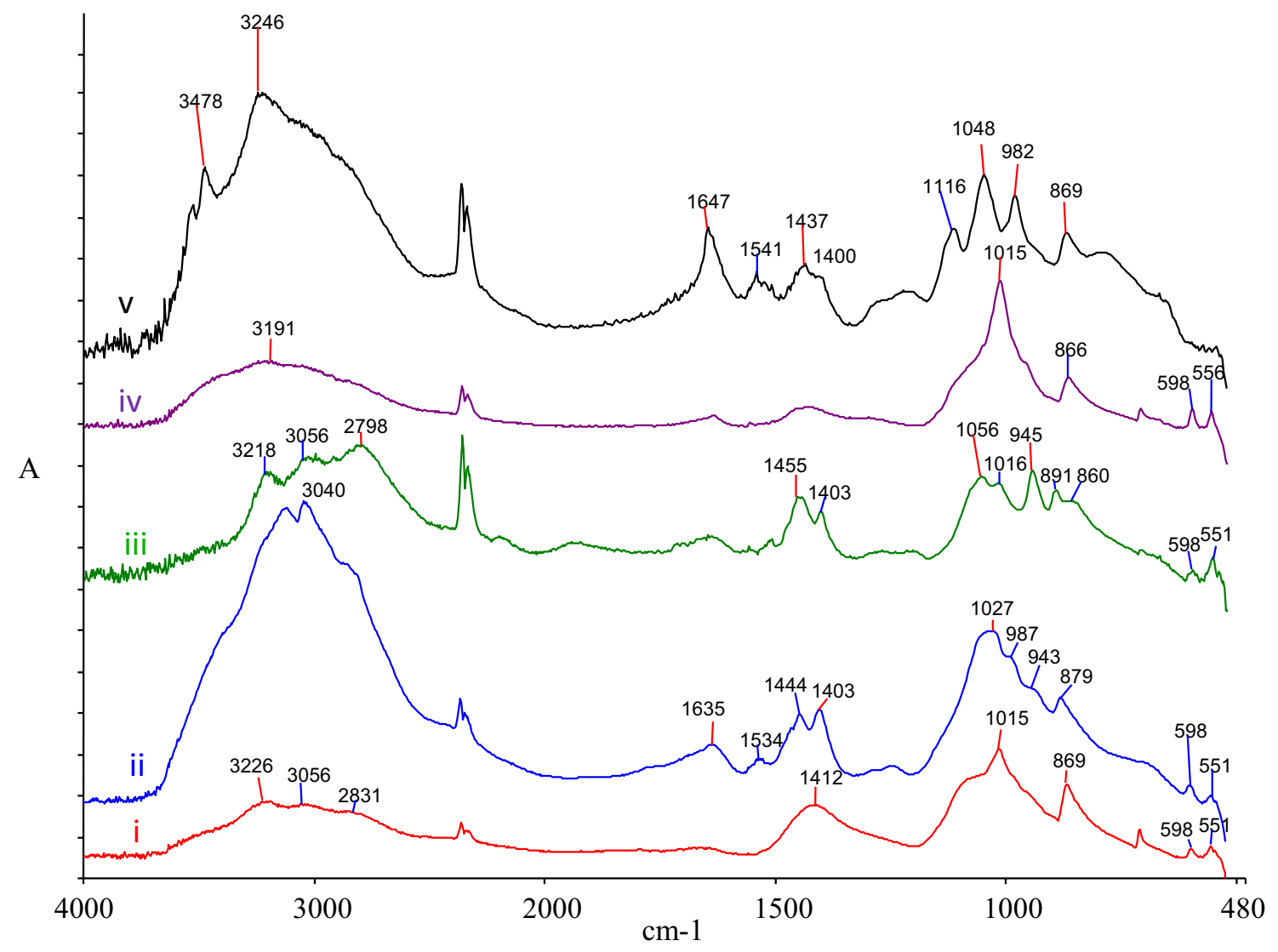

Fig. 3 ATR-FTIR spectra of product formation on pressed powdered $\mathrm{CaCO}_{3}$ discs after trials $\mathrm{Ca}-1,2,3$ and 4; (i) after immersion in DAP, (ii) in $\mathrm{DAP} / \mathrm{SBF}$, (iii) in DAP/gelatin and (iv) in DAP/SBF/gelatin solution and (v) disc iv after further addition DAP/SBF/gelatin solution

\subsubsection{Fourier transform infrared (FTIR) spectroscopy}

All samples were analyzed with a Perkin Elmer Spectrum GX spectrometer, equipped with DTGS detector. Spectra were recorded and edited with the PE Spectrum v.5.3.1 software. Further spectra editing was done using the Thermo GRAMS v.9.0 suite. For both $\mathrm{KBr}$ and ATR infrared spectra powder samples were used after manual or mechanical grinding (see Materials). The size of bone grains (see Materials and methods) assured secure measurement of the crystallinity index as warned by various researchers $[13,72,73]$.

$\mathrm{KBr}-\mathrm{FTIR}$ spectra: powder samples were mixed with potassium bromide powder ( $\mathrm{KBr}$, Merck), finely ground manually with the use of an agate pestle and mortar, and accordingly pressed into $13 \mathrm{~mm}$ discs with a hydraulic press. Disc samples were accordingly inserted in the system sample chamber for analysis.

ATR-FTIR spectra: Fourier Transform Infrared Spectroscopy (FT-IR) measurements were carried out using a Pike MIRacle single reflection horizontal ATR accessory with a zinc selenide crystal $\left(4000-525 \mathrm{~cm}^{-1}\right)$ introduced in the sample chamber of the PE Spectrum GX system using the DTGS detector.

Infrared Indices: Spectra in Figs. 1, 2, 3, 4 and 7 are shown as normalized at the $v_{3}$ phosphate band $\left(\sim 1020 \mathrm{~cm}^{-1}\right)$. Collagen and carbonate indices were calculated by the ratios of the absorbance heights at 1660 and $1415 \mathrm{~cm}^{-1}$, correspondingly, over the $v_{3}$ of phosphate at $1020 \mathrm{~cm}^{-1}$; baseline was set at 1900 and $1380 \mathrm{~cm}^{-1}$. The crystallinity index was measured by calculated Infrared Splitting Factor (IRSF, see Introduction) derived from the doublet of the $\mathrm{v}_{4}$ vibration of hydroxyapatite, according to a standard procedure [13, $46,49,74]$, by using the equation $\left(A_{604}+A_{563}\right) / A_{590}$, where $A$ corresponds to absorbance heights at the corresponding maxima of the phosphate $\mathrm{v}_{4}$ band. The baseline was set at 800 and $500 \mathrm{~cm}^{-1}$. For all the above calculations of indices, baseline limits may significantly affect the final values $[49,73]$, and therefore they must be followed thoroughly throughout all the samples. In the present work, the baseline limits by Dal Sasso et al [49]. were adopted. The reproducibility of the method was tested by calculating the average of 7 reference bone samples; 
std error for collagen index was $\pm 0.45 \%$, for carbonate index $\pm 1.24 \%$ and for IRSF $\pm 1.07 \%$.

Deconvolution: deconvolution and peak fitting were applied on the phosphate $\mathrm{v}_{4}$ infrared band using the peak fitting routine in GRAMS/AI software (Thermo). The routine was applied after baseline correction at the limits of the $680-480 \mathrm{~cm}^{-1}$ region of spectra; a Gauss/Lorentz mixed (1:1) model at medium sensitivity and FWHH 8.0 was applied; $\mathrm{R}^{2}$ was better than 0.9990 , while std error was lower than 0.0028 in all cases. In Fig. $7 \mathrm{~b}$ and c, the 2 nd derivative is also shown for confirmation of transients.

\subsubsection{Stereo-macro-photography}

Stereoscopic macro-photographs of discs were recorded using an Olympus 110AL2X-2 WD38 stereomicroscope, using magnifications at $\times 0.67-\times 4.5$.

\subsubsection{X-ray diffractometry}

XRD spectra were recorded using an InXitu BTX II Benchtop $X$-ray Diffraction/X-ray Fluorescence system using a Cobalt cathode source $\left(\mathrm{Ka}_{1} 1.78897 \AA\right.$ $)$. Spectra were analyzed with the InXitu XPowder software and searched using the PDF2 and the XPowder Difdata reference libraries.

FWHM values were calculated using the XPowder software, employing Scherer analysis of width and shape of diffraction profiles modeled on pseudo-Voigt Gaussian curve; measurements for HAP (in the cases where no overlaps are detected) were based on the $2 \theta=31.3^{\circ}$ peak, while for OCP, these were based on the $2 \theta=37.5^{\circ}$ peak.

\subsubsection{Surface porosity measurements}

Surface porosity of samples (pressed bone powder and bone specimens) were measured through SEM Image analysis, by employing ImageJ freeware (ImageJj.net); percent porosity was expressed as the ratio (total area of pores)/(total measured area) $\times 100$. Porosity values were calculated on extracted "analyzed particles" drawing after thresholding the initial image; three different magnifications were examined fir each specimen type. Calculations showed that higher magnifications showed generally higher porosity values due to better image detail; therefore, these values were adopted in the Results section. Values from surface porosity calculations are listed in Table SI.2 (Supplementary Information).

\section{Results and discussion}

\subsection{Experimental design}

The precipitation of HAP is a demanding and slow process depending on temperature and ion concentrations because a large number of ions need to be accommodated into the unit crystal. Kinetic studies have shown that a maturing period is needed with intermediate steps involving precursor phosphate phases such as tricalcium phosphate (TCP), brushite, and OCP, before finally forming $\operatorname{HAP}[1,67,75]$. In practice, n-HAP and c-HAP, with a generally lower degree of crystallinity than s-HAP, can form; these can be confirmed through their XRD and infrared spectra $[31,58,67]$. A strategy for the synthesis of hydroxyapatite was developed to investigate the factors that control the preferential precipitation of HAP; this involves the reaction of calcium with hydrogen phosphate $\left(\mathrm{HPO}_{4}{ }^{2-}\right.$ in DAP) as a source of phosphate ions, as well as SBF and gelatin as biomimetic cofactors.

In the first place, the SBF approach was employed in our methodology as a "training" method for the synthesis of HAP (herewith shown as SBF trials) and used along with DAP and gelatin in trials. Then, to investigate the formation of HAP among other phosphates, a simple methodology involving pressed powder discs of bone powder, plain or calcium-enriched, which serves as the calcium-containing starting material; these were tested against calcium carbonate discs (control experiment) and whole bone specimens (see Materials and Techniques). The discs which serve as mock-ups, allow for (a) deposition of the precipitating product in the intergrain space, (b) controlled geometry for locating the in situ deposited HAP (surface and cross-section), (c) sufficient compactness for investigating the changes in cohesiveness as a means of mechanical endurance, (d) a convenient means for visually assessing the effectiveness of the method and (e) easy application of various analytical methods (ATR-FTIR, SEM-EDX, and finally, XRD) for the detection of products.

This design also allows for investigating bone as the source of calcium, which, in parallel, serves as a biomimetic scaffold for HAP deposition. This combined scenario suggests that some of bone calcium is sacrificed to form carbonated HAP, which, however, affects the integrity of the existing bone. Based on this, additional trials were considered employing $\mathrm{CaCl}_{2}$-pretreated bone powder discs, which leads to calcium-enrichment of the material (BPCa trials). Besides, the effect of SBF and gelatin as possible biomimetic cofactors for the formation of HAP was investigated. In all types of trials, DAP, DAP/SBF, DAP/gelatin, and $\mathrm{DASP} / \mathrm{SBF} /$ gelatin solutions were studied. 


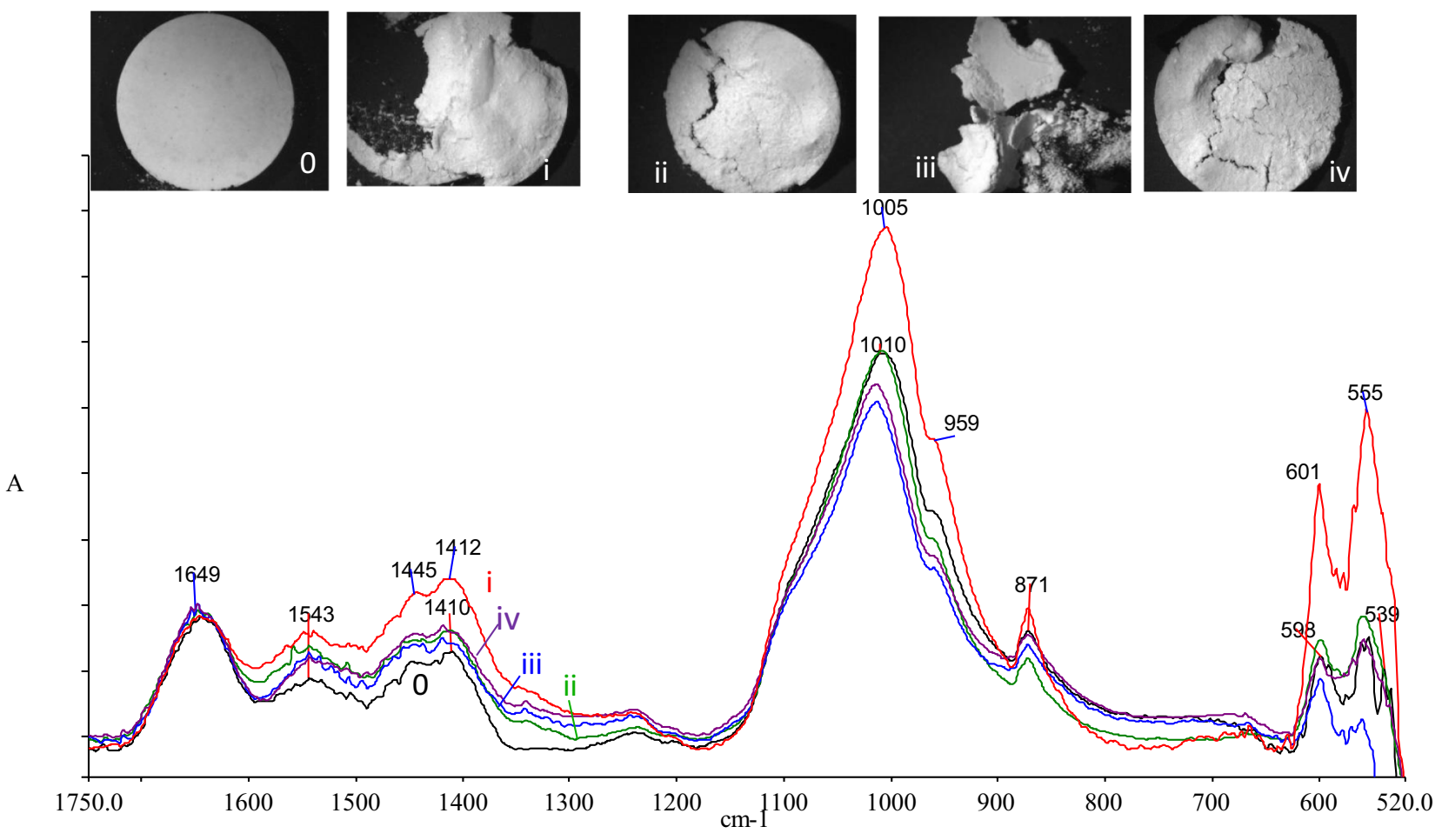

(a)

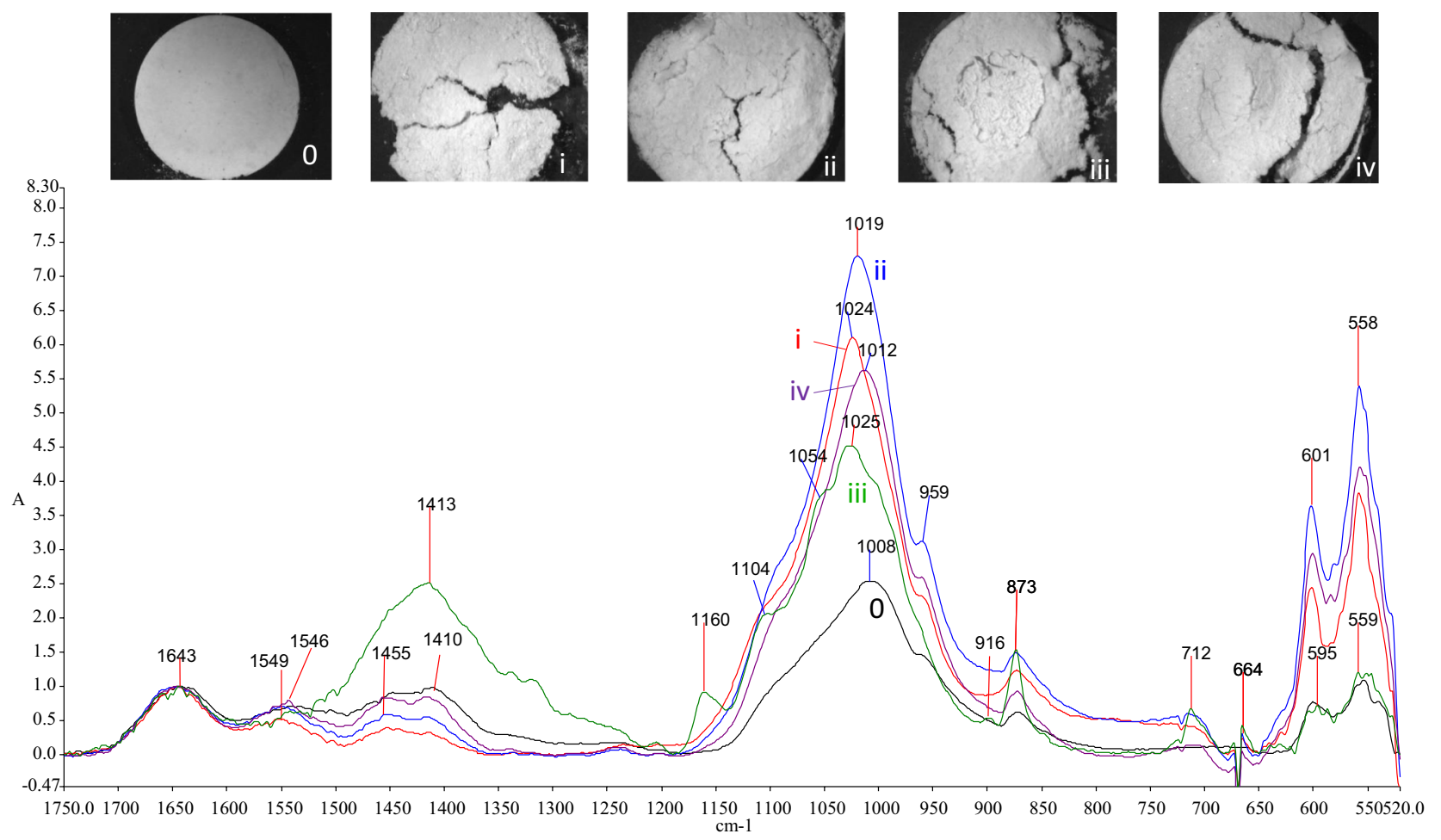

(b) 
4 Fig. 4 ATR-FTIR spectra zoomed in the $1750-520 \mathrm{~cm}^{-1}$ region, normalized at $1643 \mathrm{~cm}^{-1}$ a of products after trials BP-1, 2, 3, and 4 on pressed bone powder discs followed by water washup, and b of products after trials BPCa-1, 2, 3, and 4, on Ca-enriched bone powder discs, followed by water washup. In both spectra: (0) bone powder before treatment; after immersion in (i) DAP, (ii) DAP/SBF, (iii) DAP/gelatin and (iv) DAP/SBF/gelatin solution. Insets in both Figures: macro-photographs of discs in their initial state, (0), and after each corresponding trial, (i) to (iv)

Finally, whole bone specimens were also employed in similar trials to investigate the viability of the method on real objects. In all cases, specimens were water-washed after the reaction, which ensured the removal of all soluble starting materials, as shown through characterization with the selected techniques. The above experimental design, based on previous detailed kinetics studies, focuses on proposing favorable conditions of HAP formation as most suitable for application in the consolidation of bone.

\subsection{SBF-based wet synthesis of HAP}

Trials with SBF have been employed in the light of previous reports $[31,59,69]$ as a wet method for the biomimetic synthesis of HAP. These were, in principle, considered as a chemical process to guide the overall experimental design. Diammonium phosphate (DAP) is the reagent of choice for most research aiming at HAP synthesis so far, as its byproducts are volatile and reportedly works even in lower than physiological temperatures $[6,76]$ (trials SBF-3 to SBF-6). Additionally, disodium phosphate (DSP) has also been employed further to investigate ionic content (trials SBF-1 and SBF-2).

In addition to the above reagents, gelatin, a biomaterial derived from collagen [77-80], was also considered as a cofactor since it has been previously reported to promote the formation of HAP crystallites in a favorable molecular geometry [79, 81]. Finally, the trials were performed under stirring, as well as under no stirring, the latter being a condition for demanding applications, such as the conservation of precious heritage artefacts.

In most cases, results through $\mathrm{KBr}-\mathrm{FTIR}, \mathrm{XRD}$, and measurements of $\mathrm{Ca} / \mathrm{P}$ ratios showed that mixtures of HAP with calcium hydrogen phosphate dihydrate (or brushite) and octacalcium phosphate (OCP) were produced (trials SBF-3, and 4). In the case of the unstirred solution of trial SBF-5 with gelatin as a cofactor, HAP and OCP were formed. These two minerals, with expected $\mathrm{Ca} / \mathrm{P}$ ratios 1.67 and 1.33 , respectively, have similar infrared maxima of the prominent $v_{3}$ and $v_{4}$ phosphate vibrations $[31,32,82]$. Nevertheless, HAP and OCP can be distinguished through their XRD spectra, as shown in Fig. $2 b-d$ (the reported $2 \theta$ angles are relative to CoKa1 wavelength). The $\mathrm{d}$-spacing of $\mathrm{H}$.
AP was found at $3.3210,2.930,2.7971,2.6996$, in accordance with reported values [83], those of brushite at 7.5270, $4.1989,3.0206,2.9024,2.5997,2.4060$ and OCP at 3.4061, $2.8041,2.6122[31,84,85]$. The crystal size for brushite (Fig. 2b) was calculated at $35.3 \mathrm{~nm}$ (FWHM value calculated for the peak at D-spacing 4.1989 was 0.3070 , see Materials and Techniques), while that of HAP (Fig. 2c) at $18.0 \mathrm{~nm}$ (FWHM value for the peak at D-spacing 3.3210 was 0.6167 ). In Fig. 2d, where both products are observed, the exact calculation of crystal size is unclear.

Finally, a carbonate phase is formed in trials SBF- 4 and 5 (due to infrared bands at the $1460-1400 \mathrm{~cm}^{-1}$ range and $\sim 876 \mathrm{~cm}^{-1}$ ), possibly favored by the relatively slower diffusion imposed by the applied conditions (unstirred solutions); it is unclear to this point whether it belongs to c-HAP. Selected infrared spectra are shown in Fig. 2a, while peak assignments are listed in Table 2; abbreviated results of trials are summarized in Table 3.

The favorable effect of gelatin for producing the least soluble phases (HAP and OCP) in trial SBF- 5 may be partially explained by the relatively higher viscosity induced in the mixing solutions, which under no stirring significantly affected the kinetics of the nucleation of HAP [1, $67,75]$. As brushite and OCP are intermediate phases [33, $86,87]$, a role for gelatin in this ionic reaction could be diffusion-controlling, favoring the time-demanding precipitation of the end product. On the other hand, in the trials with disodium phosphate (DSP), almost pure brushite was the product under stirring (trial SBF-1), while HAP with a minor amount of brushite was formed with no stirring (trial SBF-2).

\subsection{In situ synthesis of hydroxyapatite on pressed powder discs}

The effectiveness of HAP formation during a heterogeneous reaction of DAP in solution with the calcium provided from bone particles was investigated by employing standard $13 \mathrm{~mm}$-discs of pressed bone powder (see Materials and Techniques and Sect. 3.A). The discs offer a convenient means for investigating the course of the reaction in situ on their surface with ATR-FTIR spectroscopy, as well as investigating the micro-morphology of the products with SEM.

\subsubsection{Pressed $\mathrm{CaCO}_{3}$ powder discs (control trials)}

The hypothesis that bone components promote HAP formation by serving as a biomimetic scaffold and simultaneously providing calcium ions to react with externally provided phosphate was evaluated and compared to control trials on pressed $\mathrm{CaCO}_{3}$ (calcite) discs. In these, calcite is the $\mathrm{Ca}^{2+}$ source, while biomimetic conditions are offered 
Table 3 Results from trials

\begin{tabular}{|c|c|c|c|}
\hline Trial \# & Description of trial ${ }^{a}$ & $\begin{array}{l}\mathrm{Ca} / \mathrm{P} \\
\text { ratios of } \\
\text { product }^{\mathrm{b}}\end{array}$ & Description of product ${ }^{c}$ \\
\hline SBF-1 & $\begin{array}{l}\text { SBF base solution; added DSP }(0.3 \mathrm{M}), \mathrm{CaCl} 2(0.5 \mathrm{M}) \text {, stirring; } 10 \mathrm{~min} \text {, } \\
\text { KBr-FTIR }\end{array}$ & 0.96 & Almost pure brushite \\
\hline SBF-2 & $\begin{array}{l}\text { SBF base solution; added DSP }(0.3 \mathrm{M}), \mathrm{CaCl} 2(0.5 \mathrm{M}) \text {, no stirring; } \\
15 \mathrm{~min}, \mathrm{KBr}-\mathrm{FTIR}\end{array}$ & 1.22 & Mixture of HAP and OCP \\
\hline SBF-3 & $\begin{array}{l}\text { SBF base solution; added DAP }(0.75 \mathrm{M}), \mathrm{CaCl} 2(1.25 \mathrm{M}) \text {, stirring; } \\
8 \mathrm{~min}, \mathrm{KBr}-\mathrm{FTIR}\end{array}$ & 1.21 & Mixture of HAP and brushite \\
\hline SBF-4 & $\begin{array}{l}\text { SBF base solution; added DAP }(0.75 \mathrm{M}), \mathrm{CaCl} 2(1.25 \mathrm{M}), \text { no stirring; } \\
10 \mathrm{~min}, \mathrm{KBr}-\mathrm{FTIR}\end{array}$ & 2.70 & Mixture of HAP and OCP; carbonate formation \\
\hline SBF-5 & $\begin{array}{l}\text { SBF base solution; added DAP }(0.75 \mathrm{M}), \mathrm{CaCl} 2(1.25 \mathrm{M}) \text {, gelatin, no } \\
\text { stirring; } 10 \mathrm{~min}, \mathrm{KBr}-\mathrm{FTIR}\end{array}$ & 1.41 & HAP-rich phase; minor carbonate formation \\
\hline Ca-1 & $\mathrm{CaCO} 3$ disc; immersion in DAP solution; $\mathrm{H}_{2} \mathrm{O}$-washup, ATR-FTIR & n.m & Mixture of HAP and brushite \\
\hline $\mathrm{Ca}-2$ & $\mathrm{CaCO} 3$ disc; immersion in DAP/SBF solution; $\mathrm{H}_{2} \mathrm{O}$-washup, ATR-FTIR & n.m & Mixture of c-HAP and brushite; higher in c-HAP \\
\hline $\mathrm{Ca}-3$ & $\begin{array}{l}\text { CaCO3 disc; immersion in DAP/gelatin solution; } \mathrm{H}_{2} \mathrm{O} \text {-washup, ATR- } \\
\text { FTIR }\end{array}$ & n.m & Mixture of HAP and brushite \\
\hline $\mathrm{Ca}-4$ & $\mathrm{CaCO} 3$ disc; immersion in DAP/SBF/gelatin solution; $\mathrm{H}_{2} \mathrm{O}$-washup & n.m & HAP \\
\hline- & Bone powder (reference), ATR-FTIR & 1.37 & Carbonate HAP \\
\hline BP-1 & Bone powder disc; added 1 drop DAP; $\mathrm{H}_{2} \mathrm{O}$-washup, ATR-FTIR & 1.37 & Mainly HAP \\
\hline BP-2 & Bone powder disc; added DAP/SBF; H2O-washup, ATR-FTIR & 1.34 & Mainly HAP \\
\hline BP-3 & Bone powder disc; added DAP/gelatin; H2O-washup, ATR-FTIR & 1.27 & Mainly HAP \\
\hline BP-4 & Bone powder disc; added DAP/SBF/gelatin; H2O-washup, ATR-FTIR & 1.30 & Mainly HAP \\
\hline BPCa-1 & $\begin{array}{l}\text { Calcium-enriched bone powder disc; added DAP; H2O-washup, } \\
\text { ATR-FTIR }\end{array}$ & 1.41 & HAP \\
\hline BPCa-2 & $\begin{array}{l}\text { Calcium-enriched bone powder disc; added DAP/SBF; H2O-washup, } \\
\text { ATR-FTIR }\end{array}$ & 1.35 & HAP \\
\hline BPCa-3 & $\begin{array}{l}\text { Calcium-enriched bone powder disc; added DAP/gelatin; H2O- } \\
\text { washup, ATR-FTIR }\end{array}$ & 1.36 & Mixture of HAP and OCP \\
\hline BPCa-4 & $\begin{array}{l}\text { Calcium-enriched bone powder disc; added DAP/SBF/gelatin; H2O- } \\
\text { washup, ATR-FTIR }\end{array}$ & 1.40 & Mixture of HAP and OCP \\
\hline- & Bird bone specimen (reference), KBr-FTIR & 1.37 & Carbonate HAP \\
\hline B-1 & Bone specimen; added DAP; 24 h, KBr-FTIR & 1.64 & Almost pure HAP \\
\hline B-2 & Bone specimen; added DAP/SBF; 24 h, KBr-FTIR & 1.26 & HAP; possibly also OCP \\
\hline B-3 & Bone specimen; added DAP/gelatin; 24 h, KBr-FTIR & 1.25 & HAP; possibly also OCP \\
\hline B-4 & Bone specimen; added DAP/SBF/gelatin; 24 h, KBr-FTIR & 1.27 & HAP; highest relative amount; possibly, also OCP \\
\hline
\end{tabular}

${ }^{\mathrm{a}}$ For experimental details, see materials and Techniques

${ }^{\mathrm{b}}$ Based on microelemental analysis through SEM-EDAX; all measurements after water washup

'Based on combined results from FTIR and XRD spectra and in comparison, to $\mathrm{Ca} / \mathrm{P}$ ratios

from cofactors SBF and gelatin. The porosity of the initial state of specimens, a crucial factor that allows for product nucleation, was measured through SEM image analysis [88-90] (see Materials and Techniques). In pressed powder disc-based trials, surface porosity can be defined as the gaps between grain boundaries, which can be related to the cohesiveness of grains of the pressed disc. In the case of pressed $\mathrm{CaCO}_{3}$ discs, surface porosity was found to be $25-30 \%$ (see Table SI.2, Supplementary Information).

In trials Ca-1, 2, 3, and 4, the immersion of pressed $\mathrm{CaCO}_{3}$ powder disks in DAP solutions (see Materials and Techniques) generally resulted in deposited material composed of HAP and brushite mixtures as identified through their $\mathrm{Ca} / \mathrm{P}$ ratios, and their ATR-FTIR and XRD spectra (Fig. 3 and Table 3). The reaction of calcite with DAP has been previously studied by atomic force microscopy (AFM), and the formation of carbonate hydroxyapatite was reported, although no further information was provided [76].

As investigated through the combined spectroscopic and elemental analysis techniques, DAP and DAP/collagen solutions (trials Ca-1, 2, and 3 ) resulted in brushite/HAP mixtures, while DAP/SBF/gelatin (Ca-4) resulted in a product mixture rich in HAP. Infrared spectra of products after 
removal of soluble components (reactants) are shown in Fig. 3. Notably, the synergistic action of gelatin with all other reagents promotes the predominant nucleation of HAP. Biomacromolecules such as gelatin allow a favorable alignment for the nucleation of HAP [30, 91], although aminoacids have been reported to inhibit HAP crystallization [92, 93], suggesting a complex multi-site mechanism concerning molecular geometries [30]. The result in the present work confirms previous findings and suggests that gelatin may be considered as a biomimetic cofactor in these applications.

Interestingly, further addition of the above reagents to the calcite powder discs (trials not shown) increased the brushite amount significantly (see, for instance, spectrum v, in Fig. 3, which shows the product of trial $\mathrm{Ca}-4$ after further addition of reagents). Scanning Electron Microscopy (SEM) images are shown in Supplementary information (Figure SI.1a), where newly formed crystal aggregates are shown as compared to reference bone.

These results also suggest possible conditions for the optimized precipitation of HAP on the surface of inorganic substrates such as limestone and marble, which have attracted significant attention in the conservation of antiquities $[4,6,94,95]$.

\subsubsection{Pressed bone powder disks (trials BP)}

Bone powder discs (see Materials and Techniques) offer a convenient medium for in situ evaluating the product formation with ATR-FTIR and SEM-EDX after the completion of reactions. Previous work has shown that in situ deposited HAP can offer consolidation to bone by reducing the porosity of (non-pressed) bone powder [7]; therefore, since HAP is precipitated in the inter-grain area of a pressed bone powder disc by similarly reducing its porosity, strengthening may be offered to the disc. Moreover, the pressing of grains during disc preparation results in cohesion for holding the hydraulically pressed disc. Surface porosities, as measured through SEM image analysis, were found to be $10.7-13.9 \%$ (see Materials and Techniques, Table SI.2).

Interestingly, a single drop of deionized water on the bone powder disc surface manages to completely disrupt the disc by separating the grains from each other. ${ }^{1}$ Based on the above, on an experimental basis, any improvement regarding the cohesiveness of discs after HAP-forming trials can be an indication for potential consolidation offered by the deposited product. However, by visual observation

\footnotetext{
${ }^{1}$ For comparison, the $\mathrm{CaCO} 3$ discs in the control trials had maintained their integrity upon the addition of water and all other reagent solutions, as well (not shown).
}

(photos in insets of Fig. 4a), discs were significantly damaged, except for the trial with DAP/SBF (BP-2) where the disc integrity was preserved; water washup for removing all soluble material did not further change the condition of the disc.

The $\mathrm{Ca} / \mathrm{P}$ ratios were found to be close to those of reference bone $(\mathrm{Ca} / \mathrm{P}=1.37$, Table 3$)$, although they cannot be solely used as a criterion $[96,97]$. FTIR spectra of trial BP-1 showed an increase in both phosphate and carbonate type $A$ and $B$ peaks, suggesting that C-HAP is formed; on the other hand, in trials (BP-2, 3, and 4), the product quantities are negligible, as compared with the initial bone spectrum (Fig. 4a). For the sake of comparison, all spectra are normalized in the amide I band of collagen. Elemental microanalysis showed minimal chlorine content after water washup, an indication first, that soluble material is removed, and secondly, that chlorapatite is not a possible product. These results suggest that calcium provided by bone powder is possibly not sufficient to ensure the integrity of the disk by forming HAP.

SEM microphotographs (Supplementary Information, Figure SI.1b) support this, by not clearly showing new crystals formation on the specimen surface, except for case BP-1 (Fig. 5b).

\subsubsection{Pressed calcium-enriched bone powder disks (trials BPCa)}

Similar trials (BPCa-1, 2, 3, and 4) were done on calciumenriched disks (see Materials and Techniques), ensuring that bone material would not be deprived of its calcium as the enrichment process would be the primary $\mathrm{Ca}^{2+}$ source. Calcium chloride was chosen because it could be easily removed with water-washup at the end of the process, and it would not interfere with the $\mathrm{pH}$ of the process, as well as with the monitoring of the entire process through infrared spectroscopy. The removal of $\mathrm{CaCl}_{2}$ after washup was tested through microelemental analysis where, in all cases, chlorine was found less than $0.9 \%$ atom (1.43 wt\%).

SEM microphotographs show the deposition of the crystalline product (crystal size 10-20 $\mu \mathrm{m}$ ) on the surface of specimens (Fig. $5 \mathrm{C}$ ). The $\mathrm{Ca} / \mathrm{P}$ ratios of products were found between 1.35 and 1.41 , close to those of reference bone (1.37).

The XRD spectra of trials BPCa- 1 and 2 showed the formation of HAP (Fig. $6 a$ and b), while BPCa-3 and 4 showed mixtures of HAP with OCP (Fig. $6 \mathrm{c}$ and d); D-spacings are shown as figures alongside peaks. HAP was found to have larger crystals as calculated through line shape analysis of XRD peaks (see Materials and Techniques); FWHM values ranged from 0.7481 (corresponding to $15.3 \mathrm{~nm}$ crystal size, trial PBCa-1) to 0.0862 (123.4 nm, trial BPCa-2). By comparison, the OCP-containing spectra (Fig. 6iii and iv) were 


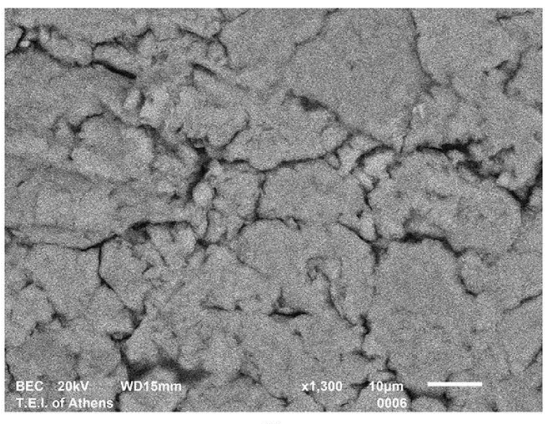

(0)

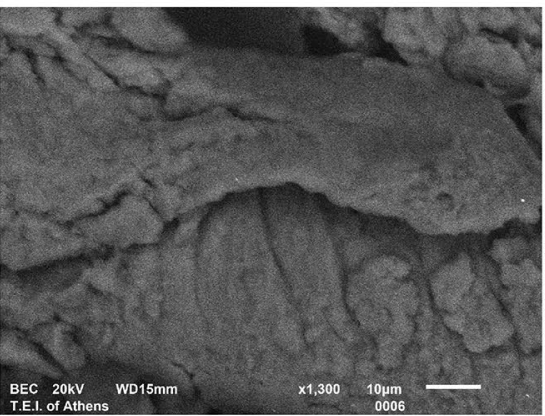

(i)

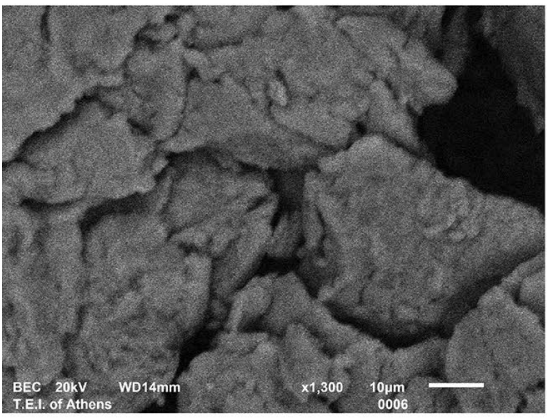

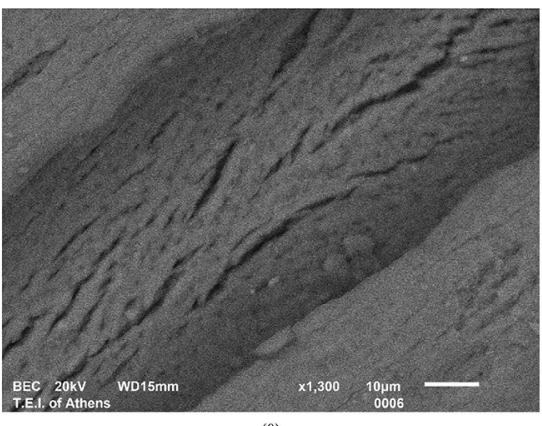

(0)

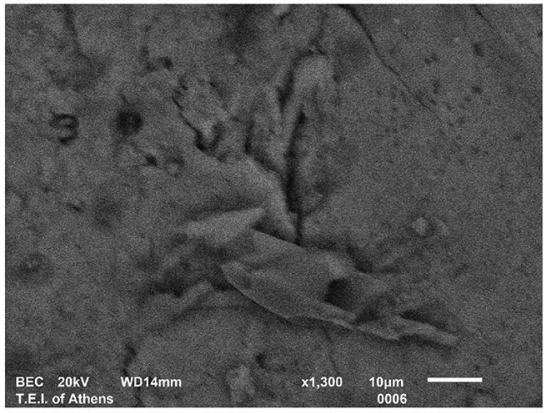

(i)

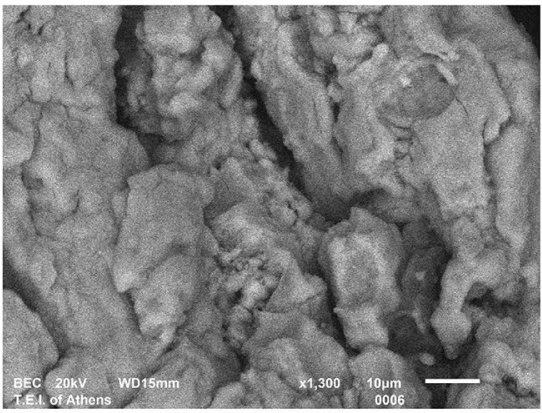

(ii)

(b)

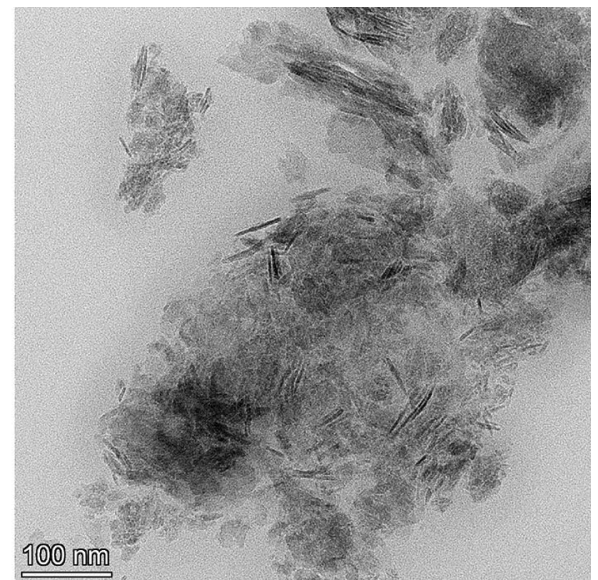

(i)

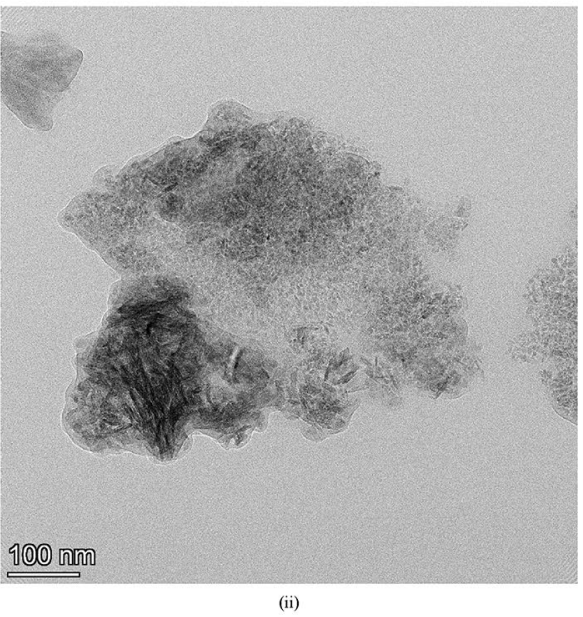

(c)
Fig. 5 a Photomicrographs of products after trials; a SEM of Caenriched bone powder discs (trials BPCa-1 and BPCa-4); b SEM of bone specimens (trials B-1 and B-4); (0) calcite disc before addition of reagents; (i) after immersion in DAP, (ii) after immersion in DAP/

broader, corresponding to significantly smaller crystals; FWHM was found to be 1.8934 (corresponding to $5.9 \mathrm{~nm}$, trial BPCa-3) and 1.8103 (6.2 nm, trial BPCa-4).

The infrared spectra (Fig. 4b) showed the HAP profile $[31,52,53]$; in particular, the IRSF values of the $v_{4}$ phosphate vibration in infrared spectra generally show higher crystallinities than those of bone reference, especially for trial BPCa-1 (see Table SI.1). Moreover, the ATR-FTIR spectra recorded on the discs showed increased phosphate phases (based on the maxima of $v_{3}$ and $v_{4}$ vibrational modes, Fig. 4b). In particular, the DAP/SBF reagent mixture (trial BPCa-2) gave the highest amount of HAP, seen through its prominent peaks at $\sim 1020 \mathrm{~cm}^{-1}$ and the doublet at $601 / 558 \mathrm{~cm}^{-1}$ in Fig. $4 \mathrm{~b}$ (i) (see Table 2 for peak assignments). On the other hand, the DAP/gelatin trial
SBF/gelatin solution. c TEM image of products on bone specimens (trials B-1 and B-4); after immersion in (i) DAP, (ii) DAP/SBF/gelatin solution

(BPCa-3) showed infrared shoulders at 1160, 1104, 1054, $916 \mathrm{~cm}^{-1}$, assignable to OCP $[30,31,82]$. Carbonate peaks of type $A\left(1455 \mathrm{~cm}^{-1}\right)$ and $B\left(1410 \mathrm{~cm}^{-1}\right)$ were detected in the product of trials BPCa-1, 2, and 4 (Fig. 4b). The carbonate index was generally lower as compared to reference bone (see Table SI1); specifically, that of trial BPCa-1 was exceptionally low. This result shows that DAP alone favors the formation of n-HAP instead of c-HAP. On the other hand, trial BPCa-3 resulted in labile calcium carbonate as detected through its uniform, unresolved $v_{3}$ maximum at $\sim 1413 \mathrm{~cm}^{-1}$.

The crystallinity index, expressed through the infrared splitting factor (IRSF, see Introduction) [11, 74, 84], was found $10-12 \%$ higher than that of fresh bone (see values in Table SI.1). HAP was found to be produced at almost 


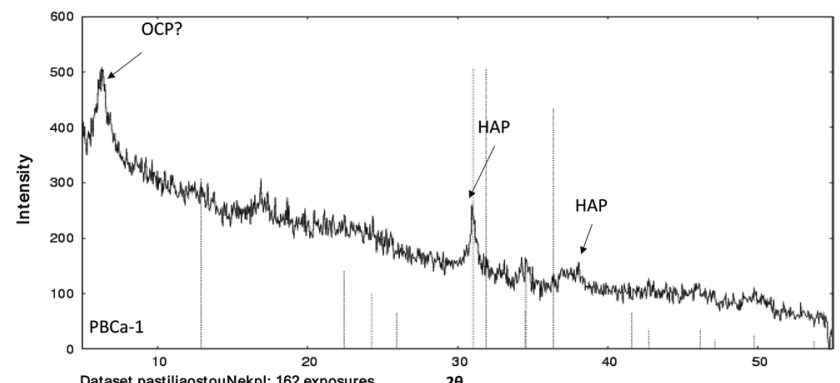

(a)

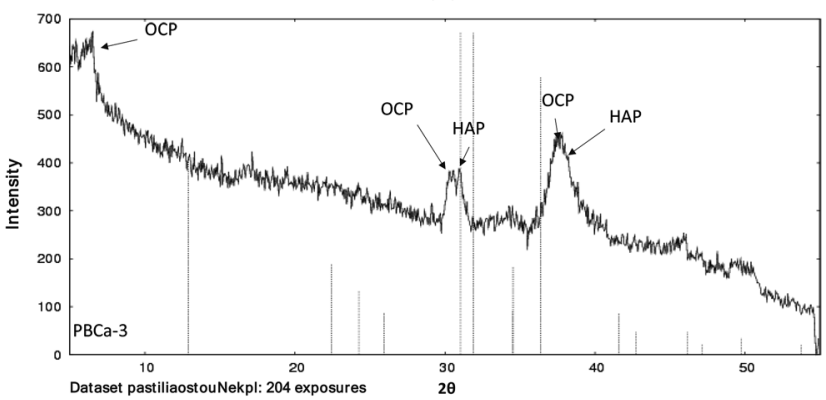

(c)

Fig. 6 XRD spectra of products on Ca-enriched bone powder discs (trials BPCa) after immersion in a DAP (trial BPCa-1), b DAP/SBF (trial BPCa-2), c DAP/gelatin (trial BPCa-3) and d DAP/SBF/gelatin

six-fold excess over that of reference bone (estimated through the collagen index, i.e., the ratio of the collagen amide I absorbance height at $1660 \mathrm{~cm}^{-1}$ over that of phosphate $v_{3}$ at $1020 \mathrm{~cm}^{-1}[49,55]$ (see Table SI1).

Through the trials on bone powder discs, the dropwise addition of reactants does not allow for long reaction times, thus restricting the observed phenomenon to its early stages. According to Ostwald's rules, more soluble, although less stable, precursor phases, such as OCP, are formed with small crystal size due to relatively fast nucleation [6, 91, 92]; these are followed by a slower nucleation stage, where HAP is formed. These experiments observe a time window where HAP starts to nucleate. For consolidation purposes, both products could work due to their comparably low solubility.

Significantly, the integrity of discs is mostly preserved in all Ca-enriched trials (insets of Fig. 4b). By comparing this observation with that of bone powder discs of trials BP1 to BP4, it seems that the extra calcium deposited on the bone grains through enrichment may be responsible for significant HAP deposition on the disks that allow better cohesion of the material.

\subsection{Whole bone specimens}

The in situ synthesis of HAP was also tested on the surface of dead bird bone specimens after immersion trials in

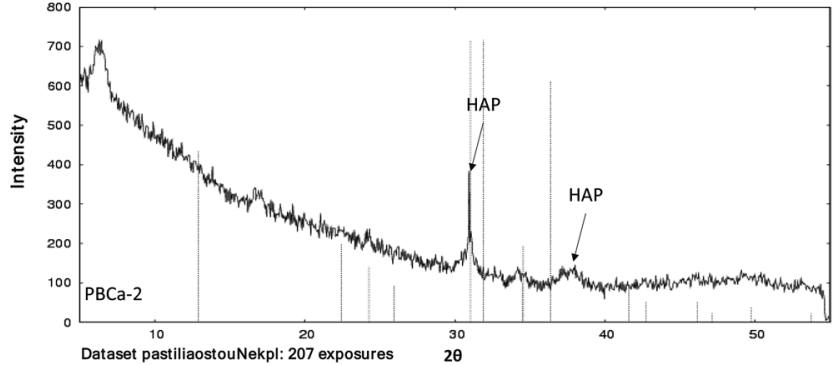

(b)

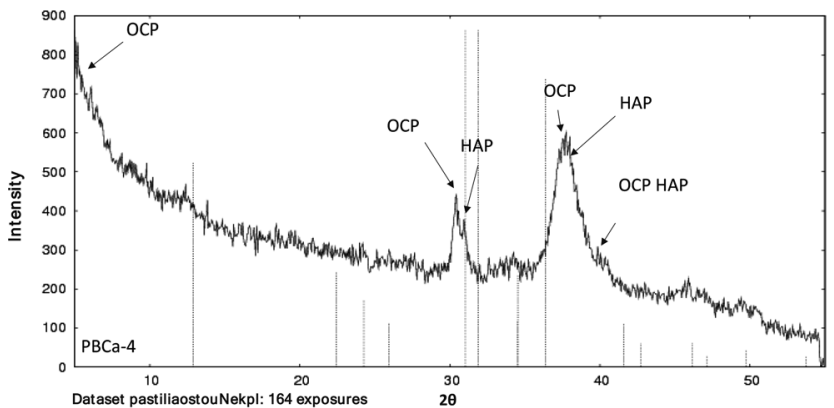

(d)

solution (trial BPCa-4). Arrows show HAP peaks; numbers alongside peaks correspond to $D$-spacings

DAP-containing solutions (see Materials and Techniques), additionally containing gelatin, SBF, and their combinations. The average surface porosity of bone was found to be approximately $15 \%$. However, as its surface is highly inhomogeneous in certain spots, such as surface grooves, high magnifications $(3000 \times$ and $5000 \times$ ) showed porosity to be as high as $21 \%$.

The deposition of white crystalline material on the bone surface was observed in all cases. After washing up the specimen surfaces with deionized water, the detached product was studied with SEM-EDX and FTIR spectroscopy. In all cases, washing up removed most soluble reactants and possible byproducts, leaving the least soluble components of the products. SEM microphotographs show product deposition on the surface of bone (Fig. 5c, photos (i-iv)) in comparison with the surface of reference (untreated) bone (photo (0), same Figure). Elemental microanalysis of the produced crystals with SEM-EDX resulted in $\mathrm{Ca} / \mathrm{P}$ ratios (Table 3 ) of approx. 1.26, while the B-1 trial, specifically, gave 1.64 , which is close to the expected ratio for s-HAP.

Transmission Electron Microscopy (TEM) bright-field images for trial B-1 (Fig. 5d) showed approx. 100-120 nm needle-like nHAP crystals $[2,57]$ formed close to smaller $(<50 \mathrm{~nm})$ original bone mineral crystals, while EDX analysis showed that elemental $\mathrm{Ca} / \mathrm{P}$ ratios ranged between 1.41-1.63. TEM image for the B-4 trial also showed nHAP 


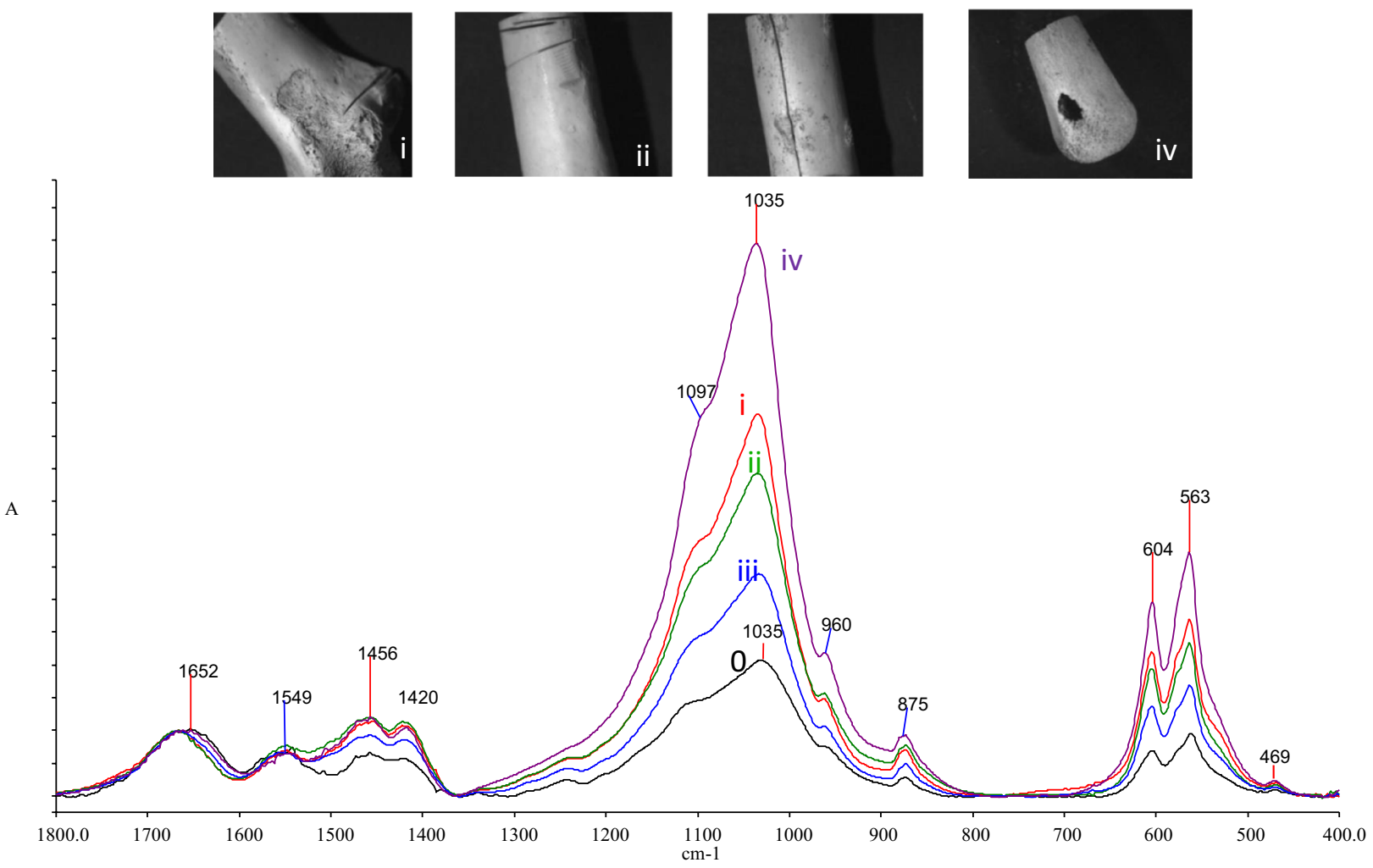

(a)

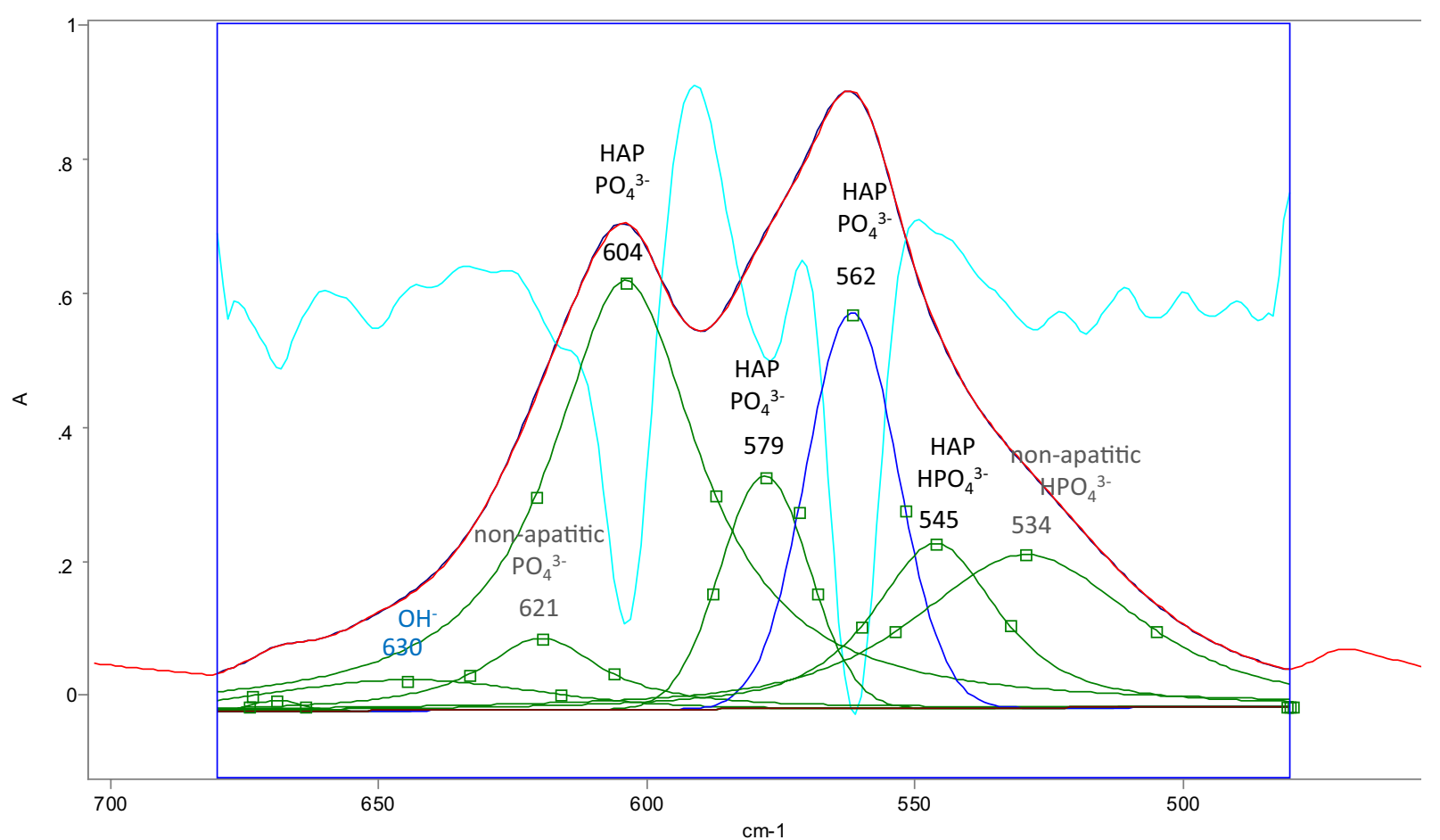

(b)

Fig. 7 a ATR-FTIR spectra from Ca-enriched bone specimens after trials $B-1,2,3$ and 4: (0) reference bone; product formation on the bone surface after immersion (i) in DAP (trial B-1), (ii) in DAP/SBF (trial B-2), (iii) in DAP/gelatin (trial B-3) and (iv) in DAP/SBF/gelatin (trial B-4) solutions. All spectra were recorded after the removal of starting material by water washup. Deconvolution and peak fitting of the phosphate $v_{4}$ vibration in $\mathbf{b}$ reference bone (spectrum a0); $\mathbf{c}$ product after trial B-1

\section{SN Applied Sciences}




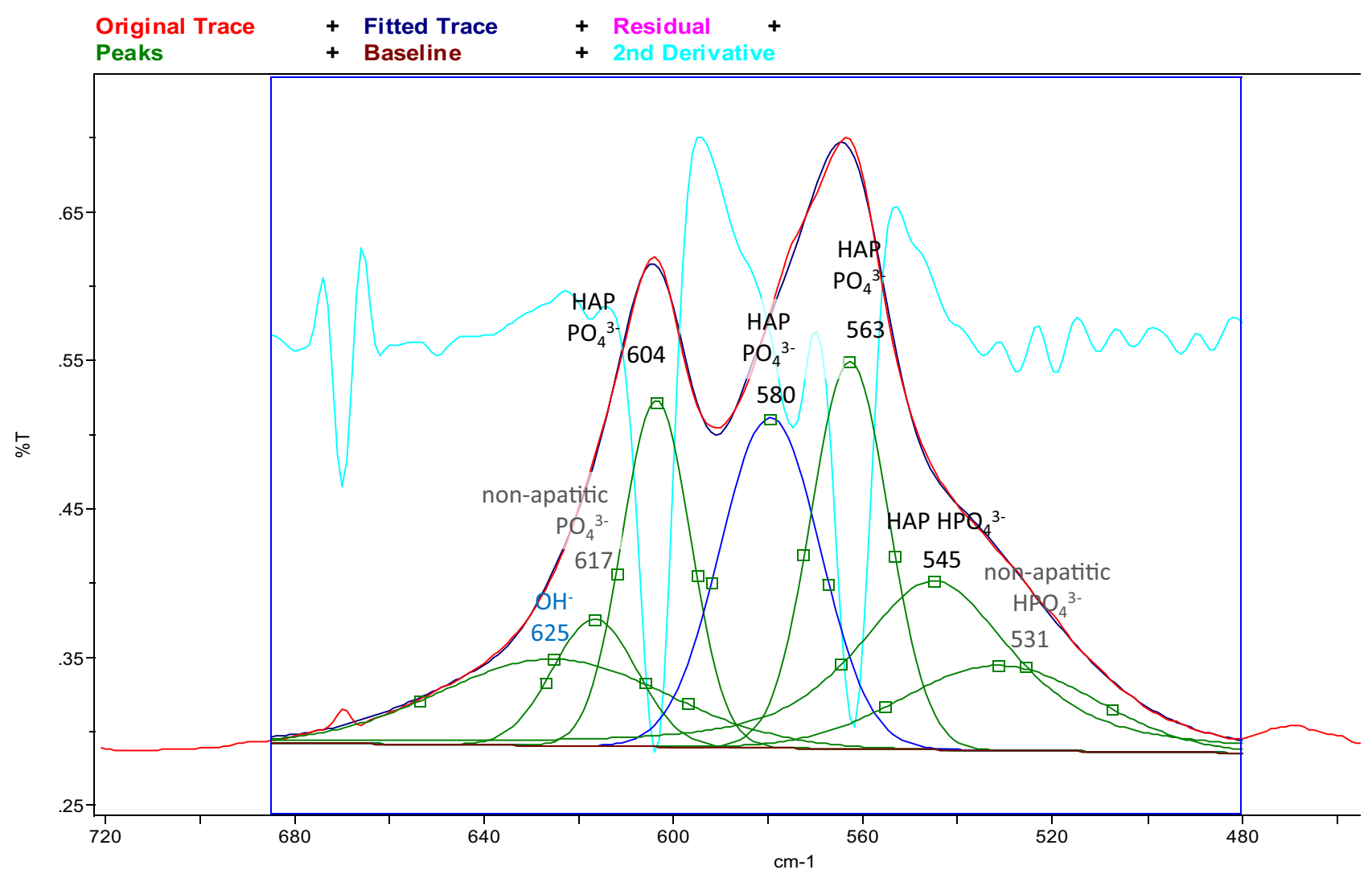

(c)

Fig. 7 (continued)

together with smaller original bone crystals, as well as a surrounding amorphous material, possibly gelatin.

The quantities of the final insoluble products did not allow for conclusive XRD spectra, as no detectable phases were measured. The FTIR spectra showed increased phosphate ( $v_{3}$ and $v_{4}$ bands) due to the formation of HAP (Fig. 7); this increase is more significant in trial B-4, due to a combined effect of the three reagents. Although the carbonate peaks generally increase as compared to collagen amide l, the carbonate index is comparably lower than that of the original bone (see Table SI1). These results suggest that although both n-HAP and c-HAP are formed, the former is preferred to the latter. The crystallinity index (IRSF value) of the product was increased by $10-12 \%$ as compared to that of reference bone (Table SI1). Moreover, deconvolution of the $\mathrm{v}_{4}$ phosphate band (Fig. $7 \mathrm{~b}$ and $\mathrm{c}$ for reference bone and product of trial B-4, respectively) shows the contributions of apatitic $\mathrm{PO}_{4}{ }^{3-}$ (at $\sim 601,575$, and $560 \mathrm{~cm}^{-1}$ ) and $\mathrm{HPO}_{4}{ }^{3-}$ peaks (apatitic at $\sim 545 \mathrm{~cm}^{-1}$, and non-apatitic at $\sim 615$ and $530 \mathrm{~cm}^{-1}$ ) [98]. In spectrum $7 c$, the higherthan-expected peaks at 578 and $541 \mathrm{~cm}^{-1}$ are possibly contributions from the $\mathrm{v}_{4}$ vibrations of co-produced OCP (cf. with values in Table 2).

The adopted experimental design and the results of this work helped in isolating factors, such as the substrate nature, the surface morphology, as well as the protein and ionic content in the molecular environment. As a significant outcome, collagen is confirmed to have a favoring effect in the nucleation of apatitic phases. Based on the hypothesis of a macromolecule-stabilized liquid phase [99], the macromolecular structure of collagen with its specific aminoacid content and sequence serves as a favorable template for the nucleation of phosphates by aligning the c-axes of apatitic crystals with the direction of collagen molecule $[81,100]$. With a hydration sphere that favors the clustering of calcium and phosphate ions due to mutual ionic attractions, a favorable ionic profile (SBF) along with the collagen or gelatin macromolecular template promotes precursor phases, such as brushite and OCP [91, 101]. The above is an early stage that eventually leads to slower, gradual nucleation of the thermodynamically more stable and relatively larger HAP crystals. The mediation of bone 
collagen, which in these experiments was assisted by externally added gelatin and SBF, signifies the biomimetic character of the process.

Although maturing time is needed for sufficient HAP formation [30], the co-precipitation of OCP in some cases could be considered not a problem for consolidation purposes, as this mineral also has a low $K_{\mathrm{sp}}$ value (Table 1).

\section{Conclusions}

This work shows that hydroxyapatite is biomimetically nucleated on the calcium-rich surfaces of pressed bone powder discs and whole bone specimens, by employing a soluble phosphate (DAP) and cofactors such as SBF and gelatin. Bone works as a biomimetic scaffold, which, aided by externally added gelatin, and SBF directs calcium, phosphate, and eventually carbonate ions to nucleate into carbonate hydroxyapatite (c-HAP), along with precursor phases, such as octacalcium phosphate (OCP). In cases where reaction times were long enough (whole bone specimens), hydroxyapatite was predominantly detected. Interestingly, the combined action of SBF and gelatin favored the formation of c-HAP even in the absence of bone scaffold, as findings from the controlling experiments on calcite discs suggest. In the case of trials with calcium-enriched specimens, sacrificial consumption of bone calcium was avoided, and the integrity of the disks was mostly unaffected, suggesting mechanical endurance of the resulting specimens; furthermore, the favorable role of gelatin was highlighted.

The results show that this strategy is promising for the consolidation of deteriorated bone. At the same time, they encourage for further optimization by exploring the gelatin factor, by replacing calcium chloride by calcium hydroxide, and by controlling diffusion and selectivity with the use of gelling agents. Moreover, a specific design for mechanical testing is needed, where the practical scope of this method will be ensured.

Acknowledgements The authors wish to thank: Dr. Jane Richter, Associate Professor at the Royal Danish Academy of Fine Arts (DRAFA), School of Conservation, Copenhagen, Denmark for supplying with Roe deer bone used in powder discs; Mrs. Eleni Tziamourani for technical assistance with grinding bone into powder; Mr. Athanasios Karampotsos, conservator, for supervision and technical assistance in the SEM-EDX facility of the University of West Attica) and Dr. Alexis Stefanis (Assistant Professor, University of West Attica) for their valuable help on experimental procedures.

\section{Compliance with ethical standards}

Conflict of interest On behalf of all authors, the corresponding author states that there is no conflict of interest.
Ethical standard No animals were tortured or sacrificed for the sample needs of this work. Roe deer bone samples were obtained through a slaughterhouse in Denmark. Naturally-aged dead seagull bone was collected after it was found in the open air.

\section{References}

1. Nayak AK (2010) Hydroxyapatite synthesis methodologies: an overview. Int J ChemTech Res 2:903-907

2. Roveri N, Foresti E, Lelli M et al (2010) Microscopic investigations of synthetic biomimetic hydroxyapatite. In: MéndezVilas A, Díaz J (eds) Microscopy: science, technology, applications and education, microscopy series $\mathrm{N}^{\circ} 4$, vol 3. Formatex Research Cente, pp 1868-1879

3. Matteini M (2008) Inorganic treatments for the consolidation and protection of stone artefacts and mural paintings. Conserv Sci Cult Herit 8:13-27

4. Sassoni E, Naidu S, Scherer GW (2011) The use of hydroxyapatite as a new inorganic consolidant for damaged carbonate stones. J Cult Herit 12:346-355

5. Scherer GW, Wheeler GS (2008) Silicate Consolidants for Stone. Key Eng Mater 391:1-25

6. Sassoni E (2018) Hydroxyapatite and other calcium phosphates for the conservation of cultural heritage: a review. Materials 11:557

7. North A, Balonis M, Kakoulli I (2016) Biomimetic hydroxyapatite as a new consolidating agent for archaeological bone. Stud Conserv 61:146-161

8. Weiner S, Wagner HD (1998) The material bone: structuremechanical function relations. Annu Rev Mater Sci 28:271-298

9. Weiner S (2010) Microarchaeology, 1st edn. Cambridge University Press, Cambridge

10. Leventouri T (2006) Synthetic and biological hydroxyapatites: crystal structure questions. Biomaterials 27:3339-3342

11. Miller LM, Vairavamurthy V, Chance MR et al (2001) In situ analysis of mineral content and crystallinity in bone using infrared micro-spectroscopy of the v4 PO4(3-) vibration. Biochim Biophys Acta 1527:11-19

12. Qin Z, Gautieri A, Nair AK et al (2012) Thickness of hydroxyapatite nanocrystal controls mechanical properties of the collagen-hydroxyapatite interface. Langmuir 28:1982-1992

13. Surovell TA, Stiner MC (2001) Standardizing infra-red measures of bone mineral crystallinity: an experimental approach. J Archaeol Sci 28:633-642

14. Lee-Thorp J (2002) Two decades of progress towards understanding fossilization processes and isotopic signals in calcified tissue minerals. Archaeometry 44:435-446

15. Kendall C, Eriksen AMH, Kontopoulos I et al (2018) Diagenesis of archaeological bone and tooth. Palaeogeogr Palaeoclimatol Palaeoecol 491:21-37

16. Nielsen-Marsh CM, Hedges REM (2000) Patterns of diagenesis in bone II: effects of acetic acid treatment and the removal of diagenetic CO32-. J Archaeol Sci 27:1151-1159

17. Hedges REM (2002) Bone diagenesis: an overview of processes. Archaeometry 44:319-328

18. Mays S (1998) The archaeology of human bones. Am Anthropol 102:175-176

19. Collins MJ, Riley MS, Child AM, Turner-Walker G (1995) A basic mathematical simulation of the chemical degradation of ancient collagen. J Archaeol Sci 22:175-183

20. Maksoud GA (2010) Comparison between the properties of "accelerated-aged" bones and archaeological bones. Mediterr Archaeol Archaeom 10:89-112 
21. Grunenwald A, Keyser C, Sautereau AM et al (2014) Novel contribution on the diagenetic physicochemical features of bone and teeth minerals, as substrates for ancient DNA typing. Anal Bioanal Chem 406:4691-4704

22. Johnson JS (1994) Consolidation of archaeological bone: a conservation perspective. J F Archaeol 21:221-233

23. Yang $F$, He D, Liu $Y$ et al (2016) Conservation of bone relics using hydroxyapatite as protective material. Appl Phys A 122:479

24. Dorozhkin SV (2011) Calcium orthophosphates. Biomatter $1: 121-164$

25. Wopenka B, Pasteris JD (2005) A mineralogical perspective on the apatite in bone. Mater Sci Eng C 25:131-143

26. Hafiz M, Matsumoto T, Okazaki M et al (2010) Biomimetic Fabrication of Apatite Related Biomaterials. In: Mukherjee A (ed) Biomimetics learning from nature. IntechOpen

27. Raucci MG, Guarino V, Ambrosio L (2012) Biomimetic strategies for bone repair and regeneration. J Funct Biomater 3:688-705

28. Palmer LC, Newcomb CJ, Kaltz SR et al (2008) Biomimetic systems for hydroxyapatite mineralization inspired by bone and enamel. Chem Rev 108:4754-4783

29. He W, Kjellin P, Currie F et al (2012) Formation of bone-like nanocrystalline apatite using self-assembled liquid crystals. Chem Mater 24:892-902

30. Gómez-Morales J, Michele I, Delgado-López JM et al (2013) Progress on the preparation of nanocrystalline apatites and surface characterization: overview of fundamental and applied aspects. Prog Cryst Growth Charact Mater 59:1-46

31. Drouet C (2013) Apatite formation: why it may not work as planned, and how to conclusively identify apatite compounds. Biomed Res Int 2013:1-12

32. Rey C, Shimizu M, Collins B, Glimcher MJ (1990) Resolutionenhanced fourier transform infrared spectroscopy study of the environment of phosphate ions in the early deposits of a solid phase of calcium-phosphate in bone and enamel, and their evolution with age. I: investigations in the v4 PO4 domain. Calcif Tissue Int 46:384-394

33. LeGeros R, Daculsi G, Orly I et al (1989) Solution-mediated transformation of octacalcium phosphate (OCP) to apatite. Scanning Microsc 3:129-137

34. Berna F, Matthews A, Weiner S (2004) Solubilities of bone mineral from archaeological sites: the recrystallization window. J Archaeol Sci 31:867-882

35. Stiner MC, Kuhn SL, Surovell TA et al (2001) Bone preservation in hayonim cave (Israel): a macroscopic and mineralogical study. J Archaeol Sci 28:643-659

36. Weiner S, Goldberg P, Bar-Yosef O (1993) Bone preservation in Kebara Cave, Israel using on-site fourier transform infrared spectrometry. J Archaeol Sci 20:613-627

37. Weiner S, Bar-Yosef O (1990) States of preservation of bones from prehistoric sites in the near east: a survey. J Archaeol Sci 17:187-196

38. Kasem MA, Yousef I, Alrowaili ZA et al (2020) Investigating Egyptian archeological bone diagenesis using ATR-FTIR microspectroscopy. J Radiat Res Appl Sci 13:515-527

39. Bayarı SH, Özdemir K, Sen EH et al (2020) Application of ATRFTIR spectroscopy and chemometrics for the discrimination of human bone remains from different archaeological sites in Turkey. Spectrochim Acta Part A Mol Biomol Spectrosc 237:118311

40. Ulian G, Valdre G, Corno M, Ugliengo P (2013) The vibrational features of hydroxylapatite and type a carbonated apatite: a first principle contribution. Am Mineral 98:752-759

41. Langford JI, Wilson AJC (1978) Scherrer after sixty years: a survey and some new results in the determination of crystallite size. J Appl Crystallogr 11:102-113
42. Muhammed Shafi P, Chandra Bose A (2015) Impact of crystalline defects and size on X-ray line broadening: a phenomenological approach for tetragonal SnO 2 nanocrystals. AIP Adv 5:057137

43. Zhu Y, Xu L, Liu C et al (2018) Nucleation and growth of hydroxyapatite nanocrystals by hydrothermal method. AIP Adv 8:085221

44. Stutman JM, Termine JD, Posner AS (1965) Vibrational spectra and structure of the phosphate ion in some calcium phosphates*, + . Trans N Y Acad Sci 27:669-675

45. Nakamoto K (2006) Infrared and Raman spectra of inorganic and coordination compounds. In: Chalmers JM, Griffiths PR (eds) Handbook of vibrational spectroscopy. Wiley, Chichester

46. Grynpas M (1976) The crystallinity of bone mineral. J Mater Sci 11:1691-1696

47. Miller LM, Vairavamurthy V, Chance MR et al (2001) In situ analysis of mineral content and crystallinity in bone using infrared micro-spectroscopy of the v(4) PO43- vibration. Biochim Biophys Acta-General Subj 1527:11-19

48. Brundavanam RK, Eddy G, Poinern J, Fawcett D (2013) Modelling the crystal structure of a $30 \mathrm{~nm}$ sized particle based hydroxyapatite powder synthesised under the influence of ultrasound irradiation from $\mathrm{X}$-ray powder diffraction data. Am J Mater Sci 3:84-90

49. Dal Sasso G, Asscher Y, Angelini I et al (2018) A universal curve of apatite crystallinity for the assessment of bone integrity and preservation. Sci Rep 8:1-13

50. El Feki H, Rey C, Vignoles M (1991) Carbonate ions in apatites: Infrared investigations in the $44 \mathrm{CO}_{3}$ domain. Calcif Tissue Int 49:269-274

51. Fleet ME, Liu X, King PL (2004) Accommodation of the carbonate ion in apatite: an FTIR and X-ray structure study of crystals synthesized at 2-4 GPa. Am Miner 89:1422-1432

52. Fleet ME (2009) Infrared spectra of carbonate apatites: v2-region bands. Biomaterials 30:1473-1481

53. Fleet ME (2017) Infrared spectra of carbonate apatites: evidence for a connection between bone mineral and body fluids. Am Mineral 102:149-157

54. Ou-Yang H, Paschalis EP, Mayo WE et al (2001) Infrared microscopic imaging of bone: spatial distribution of $\mathrm{CO}_{3}{ }^{(2-)}$. J Bone Miner Res 16:893-900

55. Chadefaux C, Le Hô A-S, Bellot-Gurlet L et al (2009) Curve-fitting Micro-ATR-FTIR studies of the amide I and II bands of type I collagen in archaeological bone materials. e-PS 6:129-137

56. Grunenwald A, Keyser C, Sautereau AM et al (2014) Revisiting carbonate quantification in apatite (bio)minerals: a validated FTIR methodology. J Archaeol Sci 49:134-141

57. Koutsopoulos S (2002) Synthesis and characterization of hydroxyapatite crystals: a review study on the analytical methods. J Biomed Mater Res 62:600-612

58. Ohtsuki C (2009) How to prepare the simulated body fluid (SBF) and its related solutions, proposed by Kokubo and his colleagues. Grad Sch Mater Sci Nara Inst 3:5-8

59. Kokubo T, Kushitani H, Sakka S et al (1990) Solutions able to reproduce in vivo surface-structure changes in bioactive glassceramic A-W3. J Biomed Mater Res 24:721-734

60. Pecheva E, Pramatarova L (2006) Modified Inorganic Surfaces as a Model for Hydroxyapatite Growth. Trans Tech Publications Ltd, Switzerland, Uetikon-Zuerich

61. Kien PT, Phu HD, Linh NVV et al (2018) Recent trends in hydroxyapatite (HA) synthesis and the synthesis report of nanostructure HA by hydrothermal reaction. In: Chun HJ, Park K, Kim C-H, Khang G (eds) Novel biomaterials for regenerative medicine. Springer, Singapore, pp 343-354

62. Shin K, Acri T, Geary S, Salem AK (2017) Biomimetic mineralization of biomaterials using simulated body fluids for bone 
tissue engineering and regenerative medicine. Tissue Eng Part A 23:1169-1180

63. Nweke CE, Stegemann JP (2020) Modular microcarrier technologies for cell-based bone regeneration. J Mater Chem B 8:3972-3984

64. Xu G, Aksay IA, Groves JT (2001) Continuous crystalline carbonate apatite thin films. a biomimetic approach. J Am Chem Soc 123:2196-2203

65. Vallet-Regi M, Navarrete DA (2015) Nanoceramics in clinical use. Royal Society of Chemistry, Cambridge

66. Arcos D, Vallet-Regí M (2020) Substituted hydroxyapatite coatings of bone implants. J Mater Chem B 8:1781-1800

67. Cuneyt Tas A (2000) Synthesis of biomimetic Ca-hydroxyapatite powders at $37^{\circ} \mathrm{C}$ in synthetic body fluids. Biomaterials 21:1429-1438

68. Kokubo T, Takadama $\mathrm{H}$ (2006) How useful is SBF in predicting in vivo bone bioactivity? Biomaterials 27:2907-2915

69. Oyane A, Kim H-M, Furuya T et al (2003) Preparation and assessment of revised simulated body fluids. J Biomed Mater Res 65A:188-195

70. Kim H-M, Kishimoto K, Miyaji F et al (1999) Composition and structure of the apatite formed on PET substrates in SBF modified with various ionic activity products. J Biomed Mater Res 46:228-235

71. Zhou Q, Su C-Y, Zheng J-J (2020) Photocatalytic HA deposition on $\mathrm{TiO}_{2}$ of $\mathrm{Ti}-0.2 \mathrm{Pd}$ surface immersed in simulated body fluid. Surf Coatings Technol 389:125649

72. Hollund HI, Ariese F, Fernandes R et al (2013) Testing an alternative high-throughput tool for investigating bone diagenesis: FTIR in attenuated total reflection (ATR) mode. Archaeometry 55:507-532

73. Kontopoulos I, Presslee S, Penkman K, Collins MJ (2018) Preparation of bone powder for FTIR-ATR analysis: the particle size effect. Vib Spectrosc 99:167-177

74. Tătar A, Ponta O, Kelemen B (2014) Bone diagenesis and ftir indices: a correlation. Stud Univ Babeş Bolyai Biol 59:101-113

75. Lin X, Li X, Fan H et al (2004) In situ synthesis of bone-like apatite/collagen nano-composite at low temperature. Mater Lett 58:3569-3572

76. Kamiya M, Hatta J, Shimada E et al (2004) AFM analysis of initial stage of reaction between calcite and phosphate. Mater Sci Eng B Solid-State Mater Adv Technol 111:226-231

77. Eastoe JE (1957) The amino acid composition of fish collagen and gelatin. Biochem J 65:363-368

78. Yakimets I, Wellner N, Smith AC et al (2005) Mechanical properties with respect to water content of gelatin films in glassy state. Polymer (Guildf) 46:12577-12585

79. Zandi M (2008) Studies on the gelation of gelatin solutions and on the use of resulting gels for medical scaffolds. Duisburg-Essen

80. Gorgieva S, Kokol V (2011) Collagen- vs. Gelatine-based biomaterials and their biocompatibility: review and perspectives. In: Pignatello R (ed) Biomaterials applications for nanomedicine. InTech, pp 1-36

81. Bigi A, Boanini E, Panzavolta S, Roveri N (2000) Biomimetic growth of hydroxyapatite on gelatin films doped with sodium polyacrylate. Biomacromol 1:752-756

82. Fowler BO, Marković M, Brown WE (1993) Octacalcium phosphate. 3. Infrared and Raman vibrational spectra. Chem Mater 5:1417-1423

83. Cullity BD, Stock SR (2013) Elements of X-ray diffraction, 3rd edn. Pearson New International Edition, Edinbourgh Gate

84. Reyes-Gasga J, Martínez-Piñeiro EL, Rodríguez-Álvarez $\mathrm{G}$ et al (2013) XRD and FTIR crystallinity indices in sound human tooth enamel and synthetic hydroxyapatite. Mater Sci Eng C 33:4568-4574

\section{SN Applied Sciences}

A SPRINGER NATURE journal
85. Nilen RWN, Richter PW (2008) The thermal stability of hydroxyapatite in biphasic calcium phosphate ceramics. J Mater Sci Mater Med 19:1693-1702

86. Zapanta Le Geros R (1974) Variations in the crystalline components of human dental calculus: I. Crystallographic and spectroscopic methods of analysis. J Dent Res 53:45-50

87. Mróz W, Bombalska A, Budner B et al (2010) Comparative study of hydroxyapatite and octacalcium phosphate coatings deposited on metallic implants by PLD method. Appl Phys A Mater Sci Process 101:713-716

88. Elsen J, Groot C (2007) Characterisation: porosity of mortars. In: Groot C, Ashall G, Hughes J (eds) Characterisation of old mortars with respect to their repair. RILEM publications SARL, Paris

89. Beningfield N, Winter N, Farrell S (2012) An interim investigation into pore formation in masonry mortar and the use of microscopy to investigate the probable initial air content. Mason Int 25:9-18

90. Shawnim P, Mohammad F (2019) Porosity, permeability and microstructure of foamed concrete through SEM images. J Civ Eng Sci Technol 10:22-33

91. Ethirajan A, Ziener U, Chuvilin A et al (2008) Biomimetic hydroxyapatite crystallization in gelatin nanoparticles synthesized using a miniemulsion process. Adv Funct Mater 18:2221-2227

92. Koutsopoulos S, Dalas E (2000) The crystallization of hydroxyapatite in the presence of lysine. J Colloid Interface Sci 231:207-212

93. Koutsopoulos S, Dalas E (2000) Hydroxyapatite crystallization in the presence of serine, tyrosine and hydroxyproline amino acids with polar side groups. J Cryst Growth 216:443-449

94. Possenti E, Colombo C, Bersani D et al (2016) New insight on the interaction of diammonium hydrogenphosphate conservation treatment with carbonatic substrates: A multi-analytical approach. Microchem J 127:79-86

95. Ma X (2017) In situ Synthesis and Characterizations of Bioceramic Based Hydroxyapatite in the Re-mineralization of Calcium-rich Matrices (PhD Thesis). UCLA

96. Sotiropoulou P, Fountos G, Martini N et al (2015) Bone calcium/phosphorus ratio determination using dual energy $X$-ray method. Phys Med 31:307-313

97. Kourkoumelis N, Balatsoukas I, Tzaphlidou M (2012) Ca/P concentration ratio at different sites of normal and osteoporotic rabbit bones evaluated by Auger and energy dispersive X-ray spectroscopy. J Biol Phys 38:279-291

98. Vandecandelaere N, Rey C, Drouet C (2012) Biomimetic apatite-based biomaterials: on the critical impact of synthesis and post-synthesis parameters. J Mater Sci Mater Med 23:2593-2606

99. Rao A, Cölfen H (2018) From solute, fluidic and particulate precursors to complex organizations of matter. Chem Rec 18:1203-1221

100. Ichikawa R, Kajiyama S, limura M, Kato T (2019) Tuning the $\mathrm{c}$-axis orientation of calcium phosphate hybrid thin films using polymer templates. Langmuir 35:4077-4084

101. Almora Barrios N (2010) A computational investigation of the interaction of the collagen molecule with hydroxyapatite. University College London

Publisher's Note Springer Nature remains neutral with regard to jurisdictional claims in published maps and institutional affiliations. 